\title{
The Plaka Bridge in Epirus: An Evaluation of New Building Materials for Its Restoration
}

\author{
Maria Apostolopoulou ${ }^{1, *}$, Ioannis Nikolaidis ${ }^{1,+}{ }^{\dagger}$ Iakovos Grillakis ${ }^{1,+}{ }^{\dagger}$ Myrto Kalofonou ${ }^{1, \dagger}$, \\ Vasileios Keramidas ${ }^{1, \dagger}$, Ekaterini T. Delegou ${ }^{1, \dagger}$, Maria Karoglou ${ }^{1, \dagger}$, Asterios Bakolas ${ }^{1, \dagger}$, \\ Kyriakos C. Lampropoulos ${ }^{1,+}\left(\mathbb{C}\right.$, Charalampos Mouzakis ${ }^{2,+}$ and Antonia Moropoulou ${ }^{1, *}$ \\ 1 School of Chemical Engineering, National Technical University of Athens, 15780 Athens, Greece; \\ gnikolaidhs95@gmail.com (I.N.); iakovosgryllakis@hotmail.com (I.G.); mirtanta@gmail.com (M.K.); \\ bkeramidas@hotmail.gr (V.K.); edelegou@central.ntua.gr (E.T.D.); margo@central.ntua.gr (M.K.); \\ abakolas@mail.ntua.gr (A.B.); klabrop@central.ntua.gr (K.C.L.) \\ 2 School of Civil Engineering, National Technical University of Athens, 15780 Athens, Greece; \\ harrismo@central.ntua.gr \\ * Correspondence: mairi_apostol@hotmail.com (M.A.); amoropul@central.ntua.gr (A.M.); \\ Tel.: +00302107723103 (M.A.); +00302107723276 (A.M.) \\ + These authors contributed equally to this work.
}

Received: 20 February 2019; Accepted: 9 April 2019; Published: 15 April 2019

\begin{abstract}
The sustainable preservation of monuments requires the use of performing materials which are at the same time compatible with the monument's historical building materials to ensure structural integrity, adequate performance of the structure in earthquake stresses, and resilience of both restoration and historical materials. This is especially true for cultural heritage assets that have experienced major destruction, demanding extensive reconstruction. The Plaka Bridge in Epirus, Greece, partially collapsed after a heavy rainfall in 2015. It was a supreme example of traditional stone bridge architecture of the region and an important landmark. In the present study, a potential restoration stone from a nearby quarry was examined in terms of compatibility in relation to the dominant historical building stone of the bridge, as well as in terms of mechanical performance, through a variety of in lab techniques. In addition, criteria were set for restoration mortars, taking into account the characteristics of the historical materials, as well as the environment of the bridge. The results of the study regarding the restoration stone and mortars are presented and assessed, in order to select the most appropriate restoration materials for Plaka Bridge in its upcoming restoration, aiming to enhance the overall resilience of the structure.
\end{abstract}

Keywords: bridge; thermal analysis (TG/DTA); microstructure (MIP); Epirus stone; natural hydraulic lime

\section{Introduction}

Stone bridges are unique structures, built since antiquity throughout the world in order to facilitate transportation through difficult landscape topographies, thus improving economic and social development of the interconnected areas [1]. Although the use of arches for bridge structures was optimized during the Roman era, with the parallel use of pozzolanic mortars to join stones together, it is a technique which has been passed along from early antiquity [2].

Today, bridge construction technology has shifted towards the use of contemporary materials such as concrete and steel, as well as towards more efficient designs (e.g., suspension bridges, cable-stayed bridges, truss bridges). As a result, traditional stone bridge construction has gradually declined, with a consequent loss of corresponding know-how and construction technology. However, the large number of existing stone bridges, at an international level, creates a considerable and invaluable stock of 
cultural heritage assets, which demands appropriate maintenance, conservation, and protection in order to ensure their preservation for future generations. Stone arch bridges in particular are in the center of significant scientific research worldwide [1-5].

Stone arch bridge structures are subjected to a number of interlinked deteriorating factors. The change in loading conditions throughout the lifespan of a bridge, nowadays more intense than the design loads of the original construction (e.g., traffic loads), is a detrimental factor for the preservation of its structural integrity and in some cases demands appropriate measures to ensure its safety [1]. The deterioration of the bridge's building materials, due to natural aging and decay mechanisms, in some cases intensified by the use of incompatible restoration materials, is an issue which must be taken under consideration, as the building materials are interlinked with the preservation state and the response of the structure as a whole [2,6]. Climate change has also played an important role in the degradation processes, as extreme rainfalls and extreme temperature variations greatly affect and accelerate degradation phenomena, especially taking into account the environment of bridge structures and the seasonal fluctuation of river levels. In some cases, incompatible reinforcement techniques can increase the rigidity of the structure, thus diminishing its response under static and dynamic loads [5]. In addition to mechanical loads, the crucial role of nonstress effects, such as temperature and moisture content, which highly affect the gradual degradation of bridge stone masonry, has also been recently highlighted [3]. The impact of these nonstress effects is highly interconnected with the building materials properties, while incompatibility between different materials may intensify the stresses developed [7].

Thus, the importance of studying the historical materials, designing proper interventions and selecting proper materials for conservation/reinforcement/restoration/rebuilding actions, is highlighted. Indeed, the characteristics of a bridge's building materials are important in assessing the response of the structure, not only under static and dynamic loads [8], but also under environmental loads, in order to achieve sustainable preservation of the structure. Indeed, feedback shows that if the initial choice of the material was properly done, the stone bridges can be maintained over time without frequent intervention [9]. Especially in the case when restoration or partial rebuilding actions are necessary, it is important to know the characteristics of both the historical and restoration materials, as well as to assess beforehand the compatibility between all materials, in order to achieve a homogeneous behavior between the different parts of the structure (historical and restored). This homogeneous behavior is in relation to both thermohygric behavior of the structure and between the different materials, as well as mechanical behavior, while other considerations, such as chemical compatibility and aesthetics, are also of paramount importance.

It should be noted, however, that studies regarding historical stone arch bridges, although of paramount importance for their preservation as cultural assets, as well as in order to satisfy safety requirements, are quite difficult, as each stone arch bridge is unique in terms of the number of arches, the shape of the arch, the arch thickness, the thickness of the piers [2], the physical properties of the fill, the building materials used (mortars and stones), the manner of construction (especially taking into account that they were built following empirical rules [4]), the diversification between construction techniques from region to region and from era to era, the characteristics of the river (water velocity, level fluctuation, etc.), the environmental conditions of the area, and the loads it must carry (e.g., vehicles). Thus, stone bridges are usually studied on a case by case basis, each field contributing in its respective area of interest-architectural analysis, geometric documentation, structural analysis, materials characterization, nondestructive evaluation - while in many cases, a multidisciplinary approach is applied, incorporating and merging data from more than one field of interest $[1,4,10,11]$. It must be noted that in recent years, a successful effort has been made in grouping and evaluating selected stone arch bridges, with parametric analysis providing useful and crucial information [2].

In the region of Epirus, Greece, stone bridges hold an important place in traditional architecture. Over three hundred natural stone bridges have been registered in the wider region of Western Thessaly and Epirus, the most mountainous part of Greece [12]. Many of them were constructed during the 
last two centuries, while many others were constructed even earlier. The use of bridges in the region of Epirus has been mandatory since antiquity, due to the mountainous topography and the large number of rivers in combination with the local environmental conditions (region with the heaviest rainfall in Greece). The masonry of these bridges is subject to various environmental factors, while in most cases, it is not protected by plaster. The extreme temperature variations of the region $(-10$ to $40{ }^{\circ} \mathrm{C}$ ), in combination with rainfalls and wind action, cause the joint mortars to deteriorate in the bed joints, while water percolating through the arch causes stones to detach, especially in the center [13]. Some of the traditional Epirus bridges were severely damaged during World War II, while the use of incompatible materials during modern restorations aggravated their deterioration.

The bridge of Plaka, built over the river Arachthos in Epirus, is a traditional one-arch stone bridge with two relieving arches on each side of the main arch (Figure 1a), protected by law as a landmark monument [14]. In its current position and form, it was built in 1863 and 1866, the latter under the supervision of the famous local builder Constantinos Bekas. It was the longest-span single-arched bridge in the Balkans, until it partially collapsed after a heavy rainfall in February 2015 (Figure 1b). Today, the only remaining non-collapsed parts are the western abutment, including part of the western side of the main arch, as well as a smaller part of the eastern abutment, whereas large fragments of the bridge have been retrieved from the river and are stored in a nearby area.

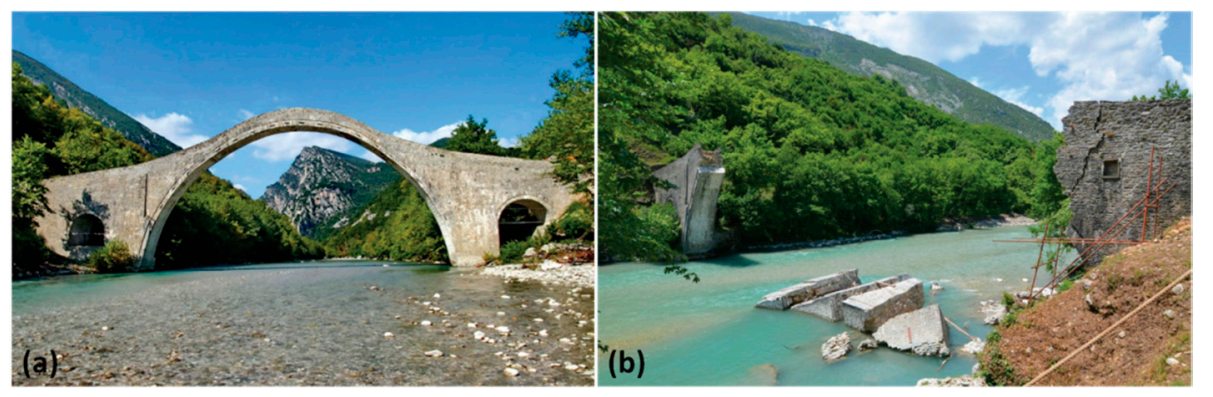

Figure 1. Images of the Plaka Bridge, (a) before its collapse, where one can see the main arch and the two relieving arches on each side, (b) and after its collapse in 2015 (adapted from [15]).

The National Technical University of Athens (NTUA), whose founders were descended from the Epirus region, immediately undertook an interdisciplinary study, pro bono, to acquire knowledge regarding the historic materials and construction techniques implemented for the construction of the bridge in the 19th century. This information was considered important, not only in relation to the historical value that it reveals, regarding historical aspects such as traditional construction technology aspects of the era, but also in relation to the restoration of the bridge, regarding the reasons for its collapse and the proposal of appropriate techniques and materials for its restoration, which will ensure compatibility with the historical materials still in place, as well as performance, aiming at the overall sustainability of the restoration. Crowd sourcing was employed in order to acquire as many photographs as possible of the bridge before collapse [14], while at the same type, different NTUA schools acquired the data necessary for documentation, diagnosis, and the basis for a restoration plan [15]. All studies were delivered to the Hellenic Ministry of Culture and Sports in order to assist in the upcoming restoration works. The study showed that the causes for collapse were synergistic: Some problems in its geometry, the extreme environmental conditions during collapse, the ferocity of the river at that time, problems in the foundations, the deterioration of its joint mortars, the use of incompatible materials in recent restorations, as well as past damages due to an explosion in the WWII, acted synergistically towards its collapse. The partial collapse of the Plaka Bridge is an example of how monuments and historical structures will in the future be affected by climate change and its detrimental effects.

This initiates a main discussion about whether it is more feasible and beneficial to restore a partially collapsed bridge at its current location and in its current form or whether it is more appropriate 
to preserve the non-collapsed parts and reconstruct a new bridge in a nearby location. The decision on the most appropriate approach is complex and typically influenced by two main factors-the historic value of the bridge in combination with the desire of the local community, as well as technical restraints. In cases where bridges have a significant historic value and cultural content, it is often decided to restore the bridge, embedding existing parts, and in most cases, following basic attributes of the historical bridge (architecture, geometry, materials, etc.) [16]. However, in some cases, technical restraints and safety issues prevail, leading to the construction of a new bridge in a nearby location, either following the original attributes of the historical bridge or designing a new contemporary bridge. Of course, intermediate approaches are also adopted, as these decisions are made on a case-to-case basis.

In the case of Plaka Bridge, it was decided to restore the bridge to its original form, embedding the non-collapsed parts of the bridge, obviously in the same location. This decision was made by the relevant authorities and was based on a variety of factors: It was listed as a landmark monument prior to its collapse and thus protected by the Greek law; it holds high historical and cultural significance, both for the local community and for the region's architecture; it was a pole of tourism attraction, and its restoration will have a positive impact on the development of tourism in the region with the respective positive economic impact. In addition to the above, surveys were conducted in order to study and understand the desire of the local society regarding the preferred approach of the Plaka Bridge restoration; a particular study revealed that $85 \%$ of the people desired the reconstruction of the Plaka Bridge [17]. This is indicative of society's need for "re-establishment of the connection" by restoring the "connection vessel".

The current study, within the upcoming restoration framework as described above, focuses on the evaluation of restoration materials in terms of compatibility and effectiveness. A quarry stone from the region of Epirus, near the Plaka Bridge (referred to as "Dafnoula stone"), was examined in terms of mineralogical, chemical, hygric, mechanical, and aesthetic characteristics and compared with the dominant historical stone of the monument in order to assess its compatibility with the dominant historical building stone of the structure, while criteria were set for restoration mortars. Restoration mortars were designed for this purpose, through the defined criteria, and were examined and evaluated for use in the upcoming restoration project in terms of compatibility and performance, aiming at an integrated approach in relation to the selection of the most appropriate restoration materials, which will serve well under the environmental factors, taking into account the historical materials and aiming to enhance the sustainability of this important historical structure and landmark of the region.

\section{Materials and Methods}

In the current study, various techniques were used to examine the characteristics of the historical stones of the bridge and the characteristics of a local quarry stone, as well as in order to study various restoration mortars up to 3 months curing. X-ray diffraction, using a Bruker D8 Advance, was used to examine mineralogical composition [18-20] of the stone specimens, both historical and quarry. Simultaneous thermal analysis (thermogravimetry and differential thermal analysis) was conducted to achieve the compositional analysis of the historical and quarry stone, as well as to study the evolution of the restoration mortars' chemical phases in relation to curing time, using a Regulus 2500, in a temperature range of $30-1000{ }^{\circ} \mathrm{C}$ with a temperature increase of $10^{\circ} \mathrm{C} / \mathrm{min}$, which is considered as optimal for the analysis of these types of materials [19]. Mercury intrusion porosimetry, using a Pascal 400 Thermo-Electronics-Corporation, was implemented to examine microstructural characteristics of both stones, historical and quarry, as well as of the restoration mortars at 3 months curing $[18,21]$. The hygric properties of the stone specimens were examined through capillary rise tests, in accordance with EN15801 (2010) [22]. The mechanical properties of the stones were studied conducting ultrasound measurements, using a Pundit-CNS Electronics with two different transducers, a transmitter and a receiver, which were applied at the ends of the specimens, with a source pulse frequency of $54 \mathrm{KHz}$. The aesthetical characteristics of the stone specimens were evaluated though colorimetry measurements [23], 
using a Dr Lange colorimeter (LMG268), while the texture and morphology of the stone samples were examined through digital microscopy, using an i-scope Moritex.

Fresh mortar state properties, such as consistency, specific gravity, and retained water of the restoration mortars produced, were examined in accordance with EN1015 (parts 3, 6, and 8, respectively [24-26]). Finally, compressive and flexural strength tests were conducted on restoration mortar specimens at three curing times (14, 28, and 90 days) in accordance with EN 1015-11 [27], while stone tiles were cut of the quarry stone (tile dimensions: $5 \mathrm{~cm} \times 5 \mathrm{~cm} \times 2 \mathrm{~cm}$ ) and used with the different types of restoration mortars in order to examine adhesion to substrate, in accordance with EN 1015-12 [28].

\section{Results and Discussion}

In the following subsection, the characterization of the historical stones as well as the quarry stone is presented, while the restoration mortars designed and produced are evaluated in relation to the historical materials of the Plaka Bridge. Compatibility of the different materials is assessed, as well as their performance in relation to mechanical performance and under the environmental conditions of the Plaka Bridge, aiming at a sustainable restoration/reconstruction and improved resilience of the structural as a whole. The nonstress environmental factors negatively affecting the monument are freeze-thaw cycles, intense hygric cycles, and intense seasonal temperature variations; these deterioration factors require the achievement of optimum compatibility between new and historic restoration materials in order to avoid concentration of stresses between different materials. Due to the specific structure and its geometry, it is considered as important that the mortars acquire early mechanical strength.

\subsection{Characterization of Historical and Quarry Stones-Evaluation of Their Compatibility}

As already mentioned, a locally quarried calcareous sandstone is herein examined in terms of compatibility and similarity with the historical building stone of the bridge. The selection of a locally quarried stone is considered as important in terms of historical value and sustainability, at the same time optimizing the possibility of acquiring a building stone as similar as possible to the original one, and, as expected, is a practice followed in other cases of bridge rebuilding as well [29], especially in cases, as that of the Plaka Bridge, where the stone has proved to be durable in the specific environment. The parallel characterization of the historical and quarry stone in the following subsections aims to assist in the evaluation of their compatibility and follows the process described in Figure 2.

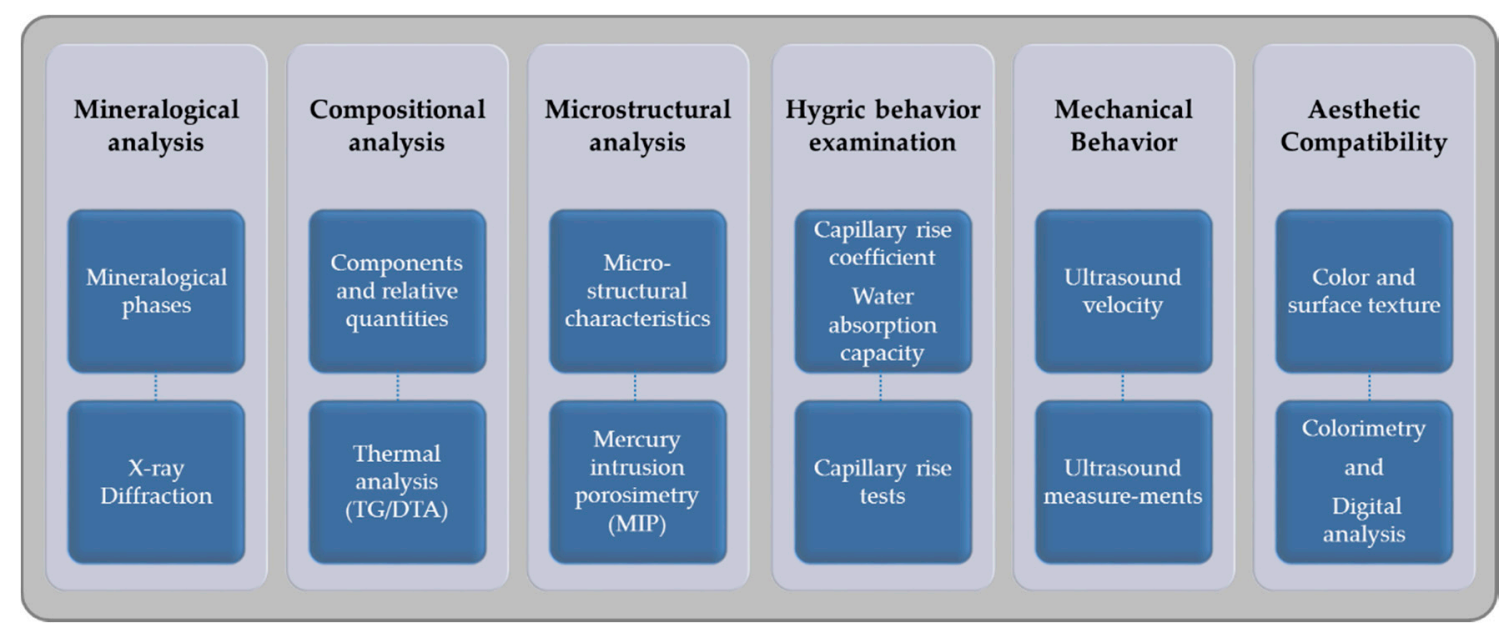

Figure 2. Flow chart of characterization of historical and restoration stone and parallel compatibility assessment. 


\subsubsection{Stone Samples' Description}

The historical stones under examination correspond to the dominant stone used in the structure (SH1, SH2), herein addressed as compact historical stone, and a porous stone used as filling material in many parts (PH1). A stone from a nearby quarry (R_S) was studied, aiming to examine its similarity with the dominant historical stone, herein addressed as quarry stone (Table 1). The selection of a stone from a nearby quarry was not random but aimed at the use of restoration materials similar to the building materials used in its 19th century construction. The stone samples were cut into cubic specimens $(5 \mathrm{~cm} \times 5 \mathrm{~cm} \times 5 \mathrm{~cm}$ ), while measurements were conducted on pulverized parts of the samples as well.

Table 1. Sample description.

\begin{tabular}{cc}
\hline Sample & Sample Description \\
\hline SH1 & Compact stone, most dominant type of the bridge's building stones \\
SH2 & Compact stone, most dominant type of the bridge's building stones \\
PH1 & Porous stone, used as filling material at interior of bridge's main body \\
R_S & Freshly cut stone from nearby quarry "Dafnoula stone" \\
\hline
\end{tabular}

The compact historical stone of the Plaka Bridge is a clastic sedimentary rock (from sand diagenesis), and specifically, it is a micaceous calcareous sandstone of grey coloration [15]. The porous historical stone is a calcareous marl of significant porosity, with pores reaching up to $1 \mathrm{~cm}$ diameter [15]. The quarry stone is a calcareous sandstone. The compact historical stone in the bridge structure presented rounded edges, an indication that during its construction in the 19th century, stones were collected from the river Arachthos, though following a strict collection process regarding their dimensions; mostly stones of dimensions 55-60 cm long and 6-12 cm thick were selected (this is especially true for stones used for the visible parts of the main arch). The final joint thickness of the mortar joining the stones is between 1-10 mm wide, depending on the curvature of the stones applied; in any case, the stones were joined closely together. In certain areas of the bridge, where filling material was used, mud-mortars combined with porous stones were detected.

\subsubsection{Mineralogical and Compositional Analysis}

The mineralogical analysis of the historical materials and the quarry stone are presented in Table 2. The compact historical stone (SH1) contains mainly quartz, with calcite as a secondary mineralogical component and an intense presence of albite, while anorthite, chlorite, montmorillonite-chlorite and muscovite were also detected. Traces of biotite, illite, chrysotile, lizardite and chlorite-serpentine were also noticed. Regarding the historical porous stone, its mineralogical composition is mostly calcite, while a small amount of quartz was also noticed.

Table 2. Mineralogical components of the examined historical and quarry stones.

\begin{tabular}{cc}
\hline Sample & Mineralogical Composition \\
\hline SH1 & Quartz, calcite, albite, anorthite, chlorite, montmorillonite-chlorite, muscovite, biotite, \\
PH1 & illite, chrysotile, lizardite, chlorite-serpentine \\
R_S & Calcite, quartz \\
\hline
\end{tabular}

The quarry stone also presented quartz as main mineralogical component and calcite and albite as secondary mineralogical phases, while traces of anorthite, montmorillonite-chlorite, illite and lizardite were also detected. Thus, the quarry stone presents a similar mineralogical composition to the compact historical building stone of the historical bridge. 
Thermogravimetric and differential thermal analysis (TG/DTA) were conducted on pulverized samples of the compact historical and quarry stone (Table 3). The mass loss until $120^{\circ} \mathrm{C}$ is attributed to dehydration processes due to release of physically bound water in the sample. In the temperature range between $120-200{ }^{\circ} \mathrm{C}$ crystalline and interlayer waters are detected. Water bound to aluminosilicates (clays etc.) was detected in the temperature range $200-600^{\circ} \mathrm{C}$. Calcite was detected in temperatures above $600{ }^{\circ} \mathrm{C}$, through the loss of $\mathrm{CO}_{2}$ produced during its decomposition.

Table 3. Thermal analysis (TG/DTA) results of compact historical stone and quarry stone.

\begin{tabular}{ccccc}
\hline \multirow{2}{*}{ Sample } & \multicolumn{4}{c}{ Mass Loss (\%) in Different Temperature Ranges } \\
\cline { 2 - 5 } & $<\mathbf{1 2 0}{ }^{\circ} \mathbf{C}$ & $\mathbf{1 2 0 - 2 0 0}{ }^{\circ} \mathbf{C}$ & $\mathbf{2 0 0 - 6 0 0}{ }^{\circ} \mathbf{C}$ & $>\mathbf{6 0 0}{ }^{\circ} \mathbf{C}$ \\
\hline SH1 & 0.35 & 0.10 & 0.72 & 11.46 \\
R_S & 0.45 & 0.11 & 1.01 & 7.67 \\
\hline
\end{tabular}

The historical stone SH1 and the quarry stone both present low values of physically bound water. As expected from the X-ray diffraction results, they both present low values of mass loss (\%) in temperatures above $600{ }^{\circ} \mathrm{C}(11.46$ and 7.67 , respectively, which corresponds to $\sim 26 \%$ and $17.5 \%$ content in calcite) and similar values of mass loss in the different temperature ranges. Thus, both stones can be considered as calcareous sandstones with moderate-to-low calcite content.

\subsubsection{Microstructural Analysis of Compact Historical Stone and Quarry Stone}

Mercury intrusion porosimetry (MIP) was implemented to study the microstructural characteristics of the dominant historical stone of Plaka Bridge and compare them with the quarry stone (Figure 3). Both compact historical stone (SH1) and quarry stone (R_S) present relatively small pores, with the historical stone presenting an accumulation of pores below $0.1 \mu \mathrm{m}$ radius and the restoration stone presenting an accumulation of pores in the area around $0.1 \mu \mathrm{m}$ radius, though again with a substantial amount of pores below this value. The values of the main characteristics for each measured sample are stated in summary in Table 4.
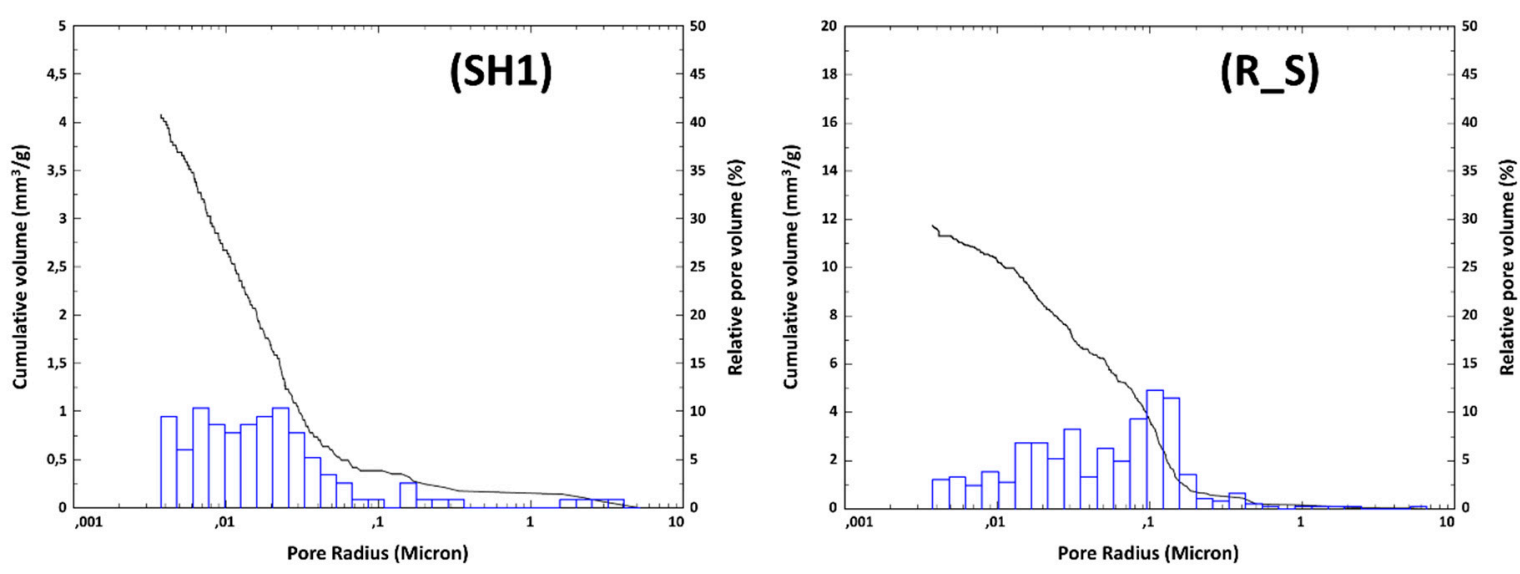

Figure 3. Mercury intrusion porosimetry (MIP) results: Compact historical stone SH1 (left) and quarry stone R_S (right).

Table 4. Microstructural characteristics of the compact historical and the quarry stone (MIP).

\begin{tabular}{cccccc}
\hline Sample & $\begin{array}{c}\text { Total } \\
\text { Cumulative } \\
\text { Volume } \\
\left(\mathbf{m m}^{\mathbf{3}} / \mathbf{g}\right)\end{array}$ & $\begin{array}{c}\text { Specific } \\
\text { Surface Area } \\
\left(\mathbf{m}^{\mathbf{2}} \mathbf{g}\right)\end{array}$ & $\begin{array}{c}\text { Average Pore } \\
\text { Radius } \\
(\boldsymbol{\mu m})\end{array}$ & $\begin{array}{c}\text { Total } \\
\text { Porosity } \\
\mathbf{( \% )}\end{array}$ & $\begin{array}{c}\text { Bulk } \\
\text { Density } \\
\left(\mathbf{g} / \mathbf{c m}^{\mathbf{3}}\right)\end{array}$ \\
\hline SH1 & 4.08 & 0.71 & 0.023 & 1.07 & 2.61 \\
R_S & 11.74 & 1.03 & 0.108 & 3.03 & 2.58 \\
\hline
\end{tabular}


The historical stone presents a very low average pore radius and a low total cumulative volume and specific surface area. Comparing the historical stone with the stone selected from the nearby quarry, it is evident that they present similar values; in particular, they present a similar bulk density, low total porosity, $1 \%$ and $3 \%$, respectively, and a low average pore radius, $0.02 \mu \mathrm{m}$ and $0.11 \mu \mathrm{m}$, respectively. The quarry stone presents a relatively higher specific surface area and cumulative volume, due to its relatively higher porosity and lower average pore radius.

In addition to the MIP measurements, the specific weight of each stone sample was calculated through dividing its weight with its apparent dimensions (average values of three cubic samples, Table 5). The predominant historical stone confirms MIP measurements and presents an extremely small standard deviation, consistent with observations of other researchers regarding its high homogeneity [15]. Two porous stones were measured, from different areas of the monument. As expected, due to the low homogeneity of this type of natural material, the standard deviation between measurements is higher than in the case of the compact stone. In fact, in the case of PH1, it is quite high, and this is attributed to the protrusion of cement grout into parts of the stone during past restoration works but not its whole mass, as determined during visual observation of the sample. Thus, one cubic specimen where cement had protruded was much heavier than the others. This is an important conclusion, as the protrusion of cement into the porous stone caused a 100\% increase in its specific weight, thus cancelling the main advantage of its use as filling material (i.e., its low specific weight and subsequently lower stresses to the lower parts of the monument).

Table 5. Specific weight of stone samples.

\begin{tabular}{ccc}
\hline Sample & Average Specific Weight $\left(\mathrm{g} / \mathbf{c m}^{\mathbf{3}}\right)$ & Standard Deviation \\
\hline SH_1 & 2.61 & 0.02 \\
SH_2 & 2.60 & 0.01 \\
PH_1 & 2.02 & 0.96 \\
PH_2 & 1.26 & 0.13 \\
R_S & 2.59 & 0.01 \\
\hline
\end{tabular}

\subsubsection{Hygric Behavior of Historical and Restoration Stones Through Capillary Rise Tests}

The hygric behavior of the compact historical stone in the structure was examined through capillary rise tests. The quarry stone was also examined in order to compare its hygric behavior in relation to the historical stone. Water transfer phenomena play an important role in the degradation of building materials, as they are connected with multiple decay mechanisms (transfer of soluble salts, bio-decay, freeze-thaw cycles, etc.) [30]. It is important that two building materials which are called upon to coexist in a structure present a similar behavior in relation to moisture uptake through capillarity and similar capillary rise coefficient, as well as a similar water absorption capacity through capillarity, especially in the case of the Plaka Bridge, which is highly affected by water transfer phenomena due to its position over a river, as well as the fluctuations of the rivers height at different epochs throughout the year.

The historical and the quarry stone present a similar behavior in relation to capillary rise (Figure 4). The quarry stone presents a slightly higher capillary rise coefficient (C.R.C.) and water absorption capacity through capillary pores $\left(\mathrm{WAC}_{\text {cap }}\right)$ in relation to the historical, though within the same value range $\left(\sim 2 \cdot 10^{-4} \mathrm{~g} /\left(\mathrm{cm}^{2} \mathrm{~s}^{1 / 2}\right)\right.$ and $<1 \%$, respectively, average of three specimens for each stone type, Table 6). 


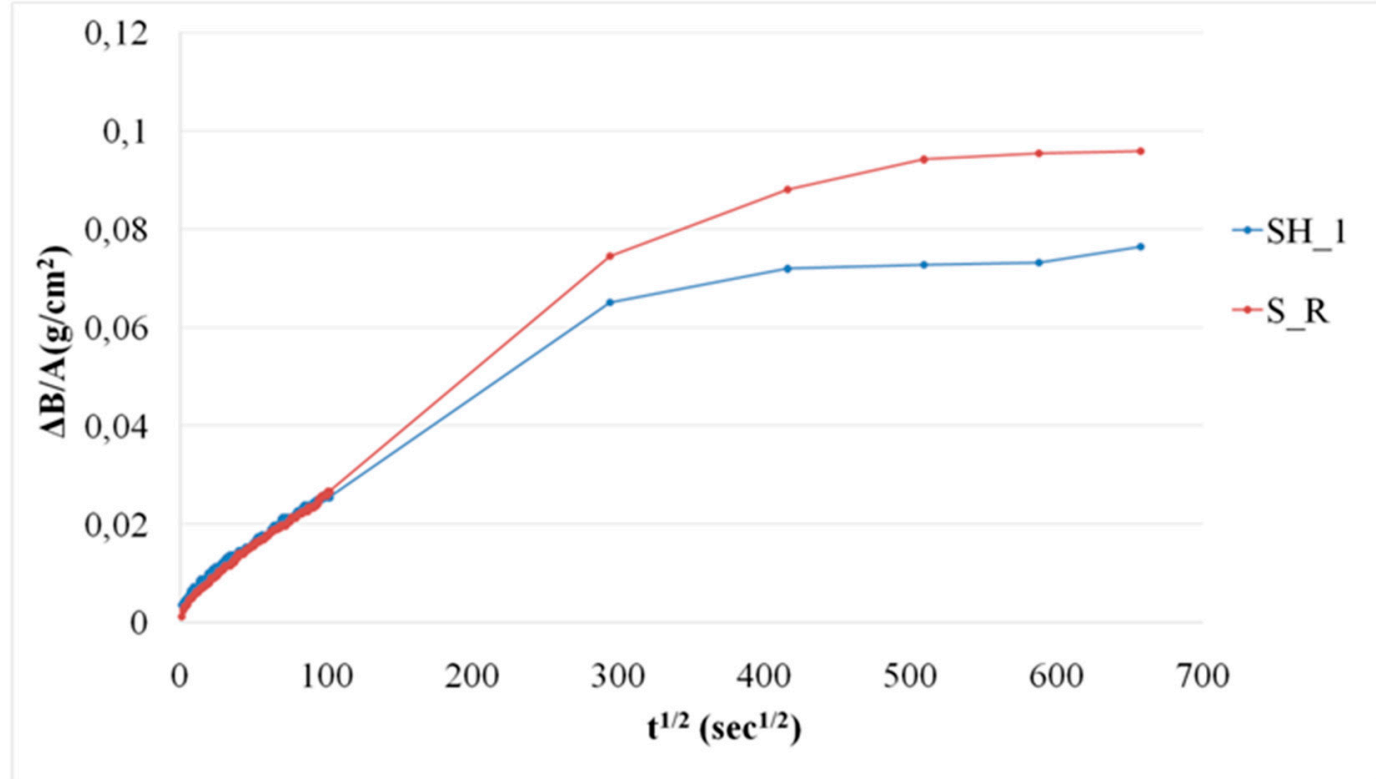

Figure 4. Characteristic capillary rise test results for historical (SH1) and quarry stone (R_S).

Table 6. Average capillary rise coefficients and average water absorption capacity through capillary rise of historical and quarry stone-with standard deviation of measurements (MIP).

\begin{tabular}{ccccc}
\hline Sample & CRC $\left(\mathrm{g} /\left(\mathrm{cm}^{\mathbf{2}} \mathbf{s e c}^{\mathbf{1} / \mathbf{2}}\right)\right)$ & St.dev. & Average $\mathbf{W A C}_{\text {cap }} \mathbf{( \% )}$ & St.dev. \\
\hline SH & $2.00 \cdot 10^{-4}$ & 0 & 0.643 & 0.068 \\
R_S & $2.33 \cdot 10^{-4}$ & $5.8 \cdot 10^{-5}$ & 0.864 & 0.090 \\
\hline
\end{tabular}

3.1.5. Mechanical Behavior of Compact Historical and Quarry Stones through Ultrasound Velocity Measurements

Ultrasound measurements were conducted on the compact historical stone (six cubic samples of SHI and SH2 - taken from different areas of the bridge-respectively, dimensions $5 \mathrm{~cm} \times 5 \mathrm{~cm} \times$ $5 \mathrm{~cm}$ ) and on the quarry stone (three cubic samples, dimensions $5 \mathrm{~cm} \times 5 \mathrm{~cm} \times 5 \mathrm{~cm}$ ). Measurements were conducted on all three directions of the cubic samples, applying the direct method. The average ultrasound velocity for all three directions of all specimens of each sample is presented in Table 7 , along with the respective standard deviation. The results are not presented in $\mathrm{x}-\mathrm{y}-\mathrm{z}$ planes, as the different planes were not discernible. The historical stones from the monument presented similar average ultrasound velocity values $(\sim 4265 \mathrm{~m} / \mathrm{s}$ and $\sim 4535 \mathrm{~m} / \mathrm{s})$, which is expected, as they are the same type of stone. The quarry stone which was evaluated regarding its compatibility and effectiveness for use in the upcoming restoration presented an intermediate ultrasound velocity value, between the two historical stones. Standard deviation of all stone samples is considered low, especially taking into consideration the fact that it is the average not only of three specimens but of all three directions of each specimen as well. This is an indication of low anisotropy of the building stones, which is desirable, as it poses an advantage regarding the response of the monument under static and dynamic loads. Thus, the restoration stone complies with a basic restoration stone selection criterion, mainly similar mechanical strength values (especially as the compact historical stone presents adequate mechanical performance) [15]. 
Table 7. Ultrasound velocity of stone samples (average value and standard deviation).

\begin{tabular}{ccc}
\hline Sample & Average Ultrasound Velocity $(\mathrm{m} / \mathrm{s})$ & Standard Deviation \\
\hline SH_1 & 4265.21 & 260.41 \\
SH_2 & 4535.05 & 177.81 \\
R_S & 4397.47 & 250.75 \\
\hline
\end{tabular}

3.1.6. Aesthetic Compatibility of Historic Stone and Quarry Stone in Relation to Color and Surface Morphology Characteristics

The historical stone and the quarry stone were examined in terms of aesthetical compatibility. Visually, the two stones presented a similar appearance, both in terms of color and surface morphology. The stone specimens, both historical and quarry stone, presented in their greatest part a greyish hue; however, discoloration was visually observed in certain areas of the historical stone, probably due to the presence of iron oxides and hydroxides.

Color measurements were conducted on five predefined spots (creating an identical "grid") of all sides of each cube, measuring six cubes for each stone type. The average values of the three color parameters are presented in Table 8 for each stone sample. The quarry stone presented a lower average lightness value than the historical stones, while it presented negative a values and positive $b$ values, similarly with the historical stone samples. As mentioned above, the historical stone presented areas where discoloration was observed even with the naked eye; these areas presented distinctly different " $a$ " and " $b$ " values in relation to the rest of the stone samples. In particular, lightness was similar in these areas (62.40 and 62.93 in areas of discoloration in comparison to 63.2 and 63.9 in gray areas); however, the "a" value, although still of negative value, was much lower in these areas of discoloration $(-0.32$ and -0.13 in relation to -1.21 and -0.98 , respectively), and the " $\mathrm{b}$ " value was much higher (4.99 and 5.35 in relation to 1.07 and 2.36 , respectively).

Table 8. Color parameter values ( $\mathrm{L}, \mathrm{a}, \mathrm{b})$ of each stone sample.

\begin{tabular}{ccccccc}
\hline Sample & L & $\begin{array}{c}\text { Standard } \\
\text { Deviation }\end{array}$ & a & $\begin{array}{c}\text { Standard } \\
\text { Deviation }\end{array}$ & b & $\begin{array}{c}\text { Standard } \\
\text { Deviation }\end{array}$ \\
\hline SH1 & 63.20 & 1.63 & -1.21 & 0.37 & 1.07 & 0.58 \\
SH2 & 63.09 & 1.60 & -0.98 & 0.50 & 2.36 & 1.80 \\
R_S & 57.49 & 1.65 & -1.77 & 0.17 & 0.98 & 0.42 \\
\hline
\end{tabular}

In order to assess the aesthetic compatibility of the two stones in terms of color parameters, the quarry stone was compared to both samples of compact historical stone (which is the stone visible in the bridge masonry) in order to estimate total color difference $\Delta \mathrm{E}$, difference in chroma $\Delta \mathrm{C}_{2,1}^{*}$ (saturation), and difference in hue $\Delta \mathrm{H}_{2,1}^{*}$ (Table 9) in accordance with the dictations of Reference [23]. Total color difference $(\Delta \mathrm{E})$ was calculated at $\sim 5.74$ and 5.82 , which is marginally above the limit value of 5 , over which it is considered that a difference in color can be perceived by the human eye. When the corrected color difference value was estimated $\left(\Delta \mathrm{E}^{*}{ }_{94}\right)$, it presented values below 5 . The difference in saturation and hue presented low values in both cases, indicating an adequate compatibility in terms of color, as a difference is desirable in order to highlight the areas of reconstruction in contrast to the preserved areas; however, the difference should be marginally apparent in order to avoid aesthetic incompatibility. Therefore, a value of $\Delta \mathrm{E}$ around 5 , in combination with low values regarding $\Delta \mathrm{E}_{94}^{*}$, $\Delta \mathrm{C}_{2,1}^{*}$ and $\Delta \mathrm{H}_{2,1}^{*}$, is considered as optimal. 
Table 9. Assessment of aesthetic compatibility between quarry stone and compact historical stone samples.

\begin{tabular}{ccccc}
\hline Sample Comparison & $\boldsymbol{\Delta} \mathbf{E}$ & $\boldsymbol{\Delta} \mathbf{E}^{*} \mathbf{9 4}$ & $\boldsymbol{\Delta} \mathbf{C}_{\mathbf{2 , 1}}$ & $\boldsymbol{\Delta} \mathbf{H}^{* \mathbf{2} \mathbf{1}}$ \\
\hline Comparison of R_S with SH1 & 5.74 & 2.91 & 0.41 & 0.39 \\
Comparison of R_S with SH2 & 5.82 & 3.19 & -0.53 & 1.50 \\
\hline
\end{tabular}

Digital microscopy, implemented to examine the morphology of the surfaces on cut cubic samples of both the historical and the quarry stone, indicated similar surface morphology between the two specimens; this was also the case in areas of discoloration due to the presence of iron oxides and hydroxides, detected microscopically on both the historical and quarry stones (Figure 5).
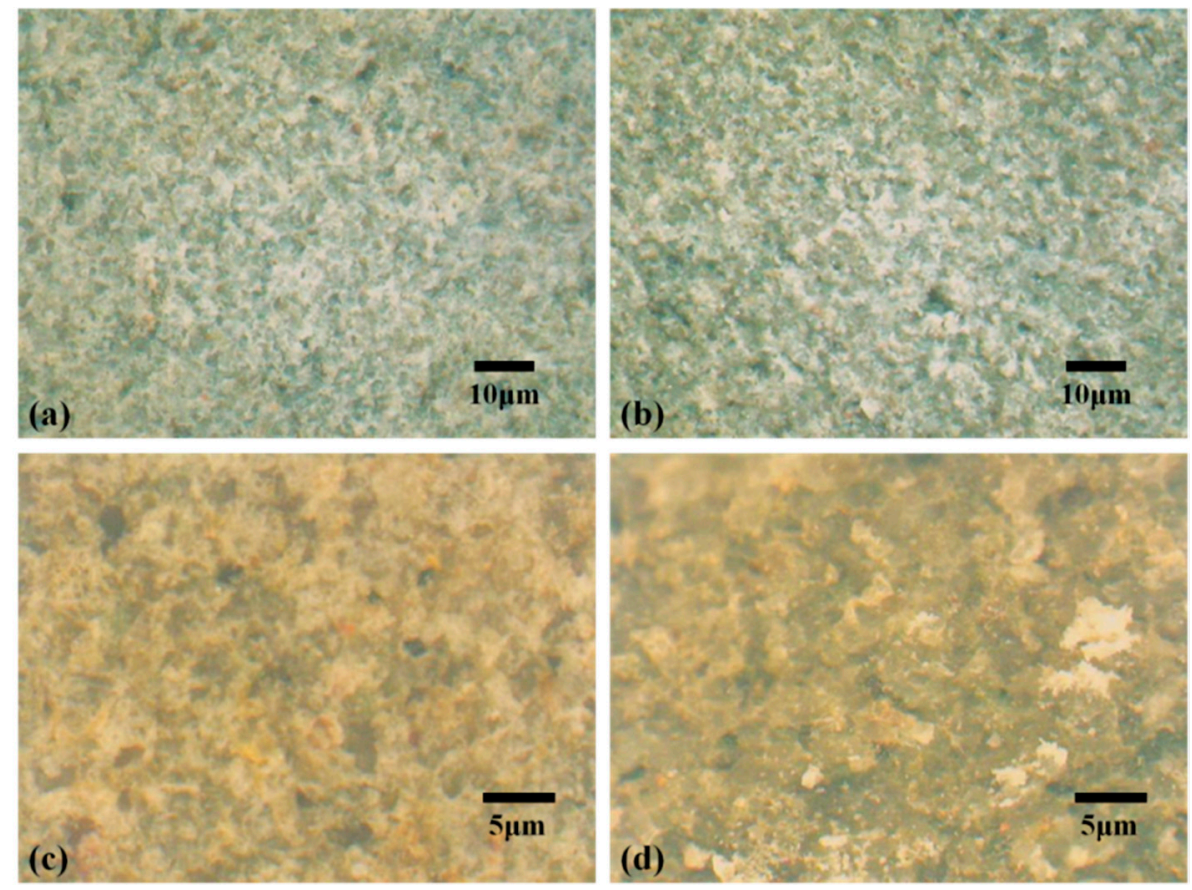

Figure 5. Digital microscopy images of the stone specimens: (a) Surface morphology of the historical stone, SH1, (b) surface morphology of the quarry stone, R_S, (c) surface morphology in area of a differentiated color, probably due to iron oxides and hydroxides, of historical stone, SH1, and (d) surface morphology in area of a differentiated color, probably due to iron oxides and hydroxides, of quarry stone, R_S.

Thus, the similarity of the two stones in relation to color and surface morphology was confirmed through colorimetry measurements and microscopic examination via digital microscopy.

\subsection{Evaluation of Restoration Mortars}

Several mortar mixes were designed in order to examine their compatibility and performance with regard to the historical building materials of the Plaka Bridge. Mortar design was based on the results of the historical mortars' analysis, through a reverse engineering approach, and was optimized mixes based on previous studies of the NTUA team in relation to the Plaka Bridge restoration [31,32].

According to previous studies [31,32], the historical mortars of the Plaka Bridge are categorized as lime-based mortars of high hydraulicity, most probably lime-pozzolan mortars produced through hot lime technology. The use of lime-based hydraulic mortars to join the stones, with the use of either hydraulic lime or aerial lime in combination with pozzolanic additives, is in accordance with common practice in bridge construction since antiquity, in the cases of course of stone arch bridges where mortar is present between the stone elements [7,33]. This is a logical selection, as lime-based 
hydraulic mortars (whether natural hydraulic lime or lime-pozzolan) have the ability to harden in high humidity environments and underwater, as well to serve well in such an environment $[34,35]$, thus also explaining the longevity they display in the abovementioned stone arch bridges. The mortars contained mostly siliceous aggregates, probably sand collected from the Arachthos river, as well as lightweight aggregates; the presence of lightweight aggregates was further confirmed through mercury intrusion porosimetry results, which measured low bulk density values for all historical mortars between $1.11-1.63 \mathrm{~g} / \mathrm{cm}^{3}$. The examined historical mortars presented inverse hydraulicity ratios between 2.84 and 9.31, their majority presenting values below the critical limit of 7 for hydraulic mortars [36], thus confirming polarized light microscopy observations regarding the presence of pozzolan in the samples [31]. The historical mortars presented high total porosity values, ranging from 31.6-48.1\%, and a small average pore radius, between $0.017 \mu \mathrm{m}$ and $0.047 \mu \mathrm{m}$, in addition to high cumulative volume values, ranging from $193.8 \mu \mathrm{m}$ to $418.1 \mu \mathrm{m}$. The mortar samples presented tensile strength values between 0.09 and $1.04 \mathrm{MPa}$, with an average value of $0.36 \mathrm{MPa}$ among all samples [37].

\subsubsection{Design of Restoration Mortars-Compatibility and Performance Criteria}

In order to design an appropriate restoration mortar, it is necessary to take the historical mortars of a historical structure into consideration. This is related to many aspects of the restoration; by using similar construction technology and materials-if, of course, the historical mortar has served adequately in the structure and its environment-one is consistent with the technological history of the structure; the restoration mortar must be compatible with the historical materials in physicochemical and mechanical terms; the restoration mortar must serve adequately and be durable in the environment of the monument, always "without surviving at the expense of the historical materials"; the structural assessment of the monument must be taken into account, to ensure that the restored monument will respond adequately in the case of dynamic stresses, the latter especially important in seismic areas such as Greece [32,38-40]. The methodology employed for the design of restoration mortars in the case of cultural heritage assets is schematically described in Figure 6.

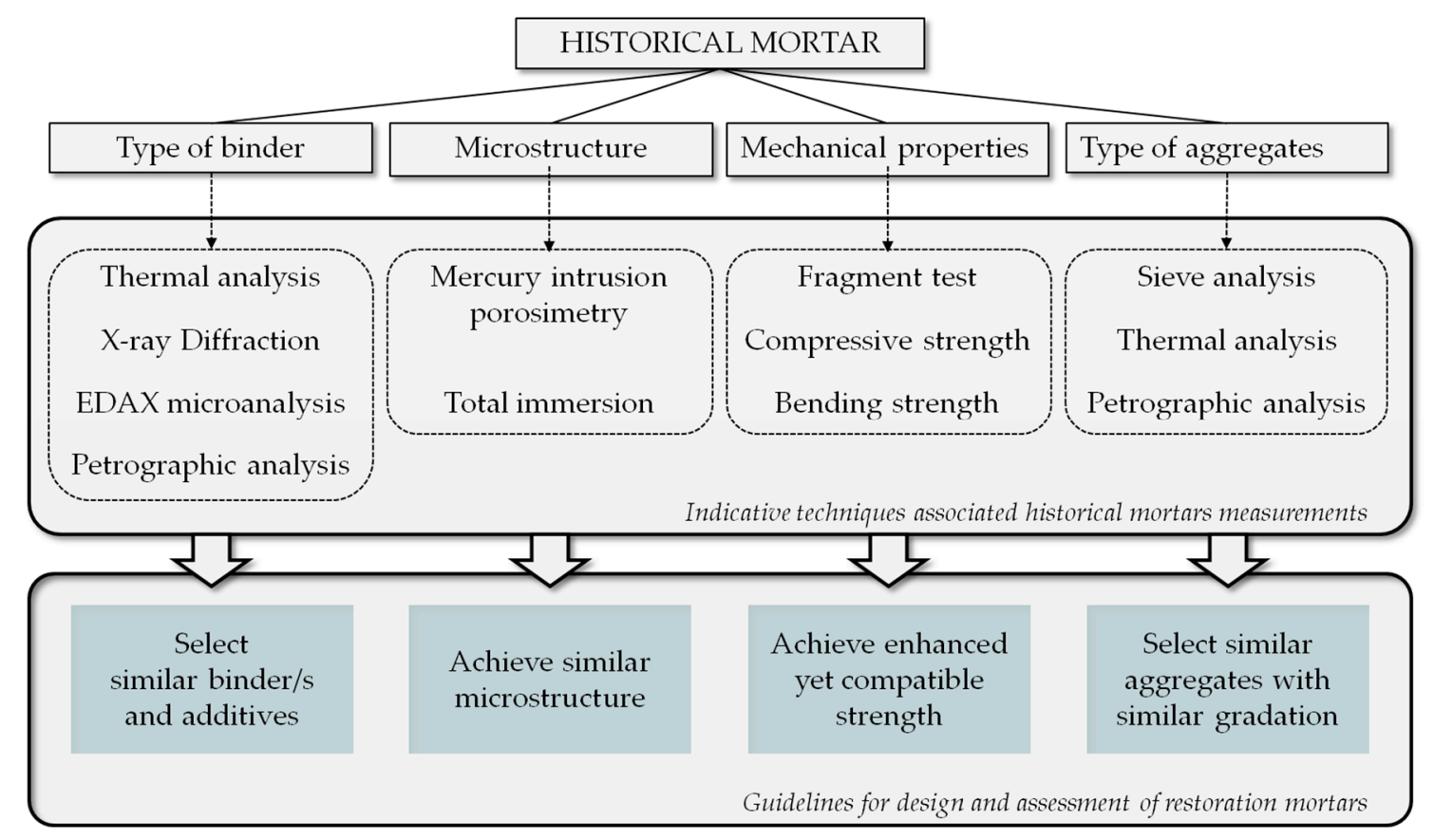

Figure 6. Schematic representation of how the analysis of historical mortars can assist in the design and assessment of restoration mortars for a specific cultural heritage asset.

In the case of the Plaka Bridge, it is obvious that in order to be consistent with the historical mortars, it would be preferable to apply a lime-pozzolan restoration mortar; this has the added 
benefit of excellent performance in high moisture environments, such as that of the Plaka bridge, as described above. Studies have shown that hydraulic lime-based mortars can also serve well in such an environment [41]. The selection of lime-pozzolan and hydraulic lime as binders for the production of the mortars is also dictated by the longevity displayed by such mortars in historical bridges. Hot lime technology is not advised to be reproduced, especially at a project of this scale, due to safety issues, in relation to the personnel applying the materials, as well as due to reproducibility issues and issues of inhomogeneity, as hot lime technology is not easily controlled due to the high temperatures developed and due to the fact that the quicklime is not homogeneously slaked and mixed with the aggregate materials. It was thus decided to use siliceous river sand in the restoration mortars mixes as aggregate material, in consistency with the historical mortars which contained mainly siliceous aggregates, and maintaining a low gradation of $0-2 \mathrm{~mm}$. The low gradation will also ensure the optimum application of the restoration mortar in the $1 \mathrm{~cm}$ joint between the building stones during the upcoming rebuilding of the bridge. In relation to physicochemical compatibility, apart from the production of hydraulic restoration mortars, in order to be consistent with the hydraulicity indices presented by the historical mortars and in order to serve adequately in the high humidity environment of the bridge, microstructural characteristics of restoration and historical mortars must be compared in order to evaluate their compatibility and ensure that their combined presence in the structure will not lead to anisotropy regarding moisture transfer phenomena.

In order to achieve the required performance from the restoration mortar, according to the requirements set by structural engineers, the restoration mortar must present $\sim 9 \mathrm{MPa}$ compressive strength. Compatibility regarding mechanical strength properties between the historical materials and the restoration mortar is related to the application of a restoration mortar which is not decisively stronger than the historical materials. If this is not achieved, the restoration mortar might survive to the expense of the historical materials, especially in the case of earthquake stresses. The historical mortars, as stated above, presented an average tensile strength value of $0.36 \mathrm{MPa}$, which corresponds to a flexural strength value of about 1.2 $\mathrm{MPa}$, while the dominant historical building stone presented compressive strength values between 50-70 MPa. Taking into account the mechanical properties of the historical mortars and stones, it must present compressive strength values not exceeding $10 \mathrm{MPa}$ in order to be considered as compatible and to ensure that the restoration mortar will not jeopardize the historical mortars, though not lower that $7 \mathrm{MPa}$, in order to maintain effectiveness of the restoration mortar. In addition, due to the specific construction, adhesive strength of the mortar becomes even more important and thus, it was studied by applying the restoration mortar with the quarry stone that is under consideration for use in the restoration project. Pull-off tests were conducted on the mortar-stone system. The optimum restoration mortar will present the highest value, and rupture must not take place within the stone.

Taking the above into consideration, restoration mortars were produced in order to examine their compatibility and performance for use in the restoration of the Plaka Bridge. The mortar mixes are stated in Table 10 and were calculated as a percentage per weight unit. The lime-metakaolin mortars were produced using aerial lime CL-90, metakaolin as pozzolanic additive (in a percentage which, considering and correlating the results from available literature, was predicted to provide the desirable compressive strength [42-44]), and siliceous sand, 0-2 $\mathrm{mm}$. The addition of superplasticizer was also examined in the case of the lime-metakaolin mortar. One mortar was produced with the use of natural hydraulic lime NHL3.5, metakaolin, and siliceous sand 0-2 mm, while two mortars were produced through the combination of hydraulic lime NHL3.5, natural pozzolan, metakaolin, and a mix of siliceous and calcareous sand $(0-2.5 \mathrm{~mm})$, with the addition of various additives, usually added by field professionals. 
Table 10. Mortar mixes examined (w/w\%).

\begin{tabular}{ccccccccc}
\hline $\begin{array}{c}\text { Restoration } \\
\text { Mortar }\end{array}$ & $\begin{array}{c}\text { Lime } \\
\text { Powder }\end{array}$ & $\begin{array}{c}\text { Natural } \\
\text { Hydraulic } \\
\text { Lime } \\
\text { NHL3.5 }\end{array}$ & Metakaolin & $\begin{array}{c}\text { Natural } \\
\text { Pozzolan }\end{array}$ & $\begin{array}{c}\text { Siliceous } \\
\text { Sand } \\
\mathbf{0 - 2} \mathbf{~ m m})\end{array}$ & $\begin{array}{c}\text { Mix } \\
\text { Sand }\end{array}$ & $\begin{array}{c}\text { Superplasticizer } \\
\text { (\%w/w of dry } \\
\text { mortar) }\end{array}$ & $\begin{array}{c}\text { Addition of } \\
\text { Additives }\end{array}$ \\
\hline L_M8.5 & 16.5 & - & 8.50 & - & 75 & - & - & NO \\
\hline L_M8.5_s & 16.5 & - & 8.50 & - & 75 & - & 0.05 & NO \\
\hline NHL_M1 & & 24.00 & 1.00 & - & 75 & - & - & NO \\
\hline Pl.Br.1 & 18.75 & 4.17 & 12.5 & - & 64.58 & 0.05 & YES \\
\hline Pl.Br.2 & 18.75 & 4.17 & 12.5 & - & 64.58 & 0.05 & NO \\
\hline
\end{tabular}

\subsubsection{Fresh Mortar Characteristics}

Water to binder ratio (W/B, where binder is calculated as the sum of lime and pozzolanic additive/s) for each mortar mix was determined after measuring the consistency of the fresh mortar by flow table [24] and aiming at a value of 15-15.5 cm. In the case of the two mortars Pl.Br.1 and Pl.Br.2, consistency was considerably higher when the same workability was achieved, probably due to the addition of the organic additives and perhaps due to the combination of the two types of pozzolan. The aforementioned mix parameters as well as the bulk density and the percentage of retained water $[25,26]$ are presented in Table 11.

Table 11. Fresh state characteristics of examined restoration mortars.

\begin{tabular}{ccccc}
\hline Restoration Mortar & W/B & Flow Table $(\mathbf{c m})$ & Bulk Density $\left(\mathbf{g} / \mathbf{c m}^{\mathbf{3}}\right)$ & Retained Water $(\mathbf{\%})$ \\
\hline L_M8,5 & 1.10 & 15.50 & 1.88 & 93.77 \\
L_M8,5s & 1.01 & 15.10 & 1.92 & 94.56 \\
NHL_M1 & 0.74 & 15.00 & 2.04 & 92.41 \\
Pl.Br.1 & 0.69 & 16.50 & 1.82 & 99.02 \\
Pl.Br.2 & 0.65 & 16.80 & 1.97 & 89.88 \\
\hline
\end{tabular}

The lime-metakaolin mortar, with and without superplasticizer, presented the highest demand of mixing water in relation to binder materials, with the addition of the superplasticizer decreasing water demand. However, these mortars presented adequate percentage of retained water, higher even than the value demonstrated by the natural hydraulic lime mortar, which had a much lower demand in mixing water. The lowest demand in water was demonstrated by Pl.Br.1 and Pl.Br.2, with the mortar with the addition of a mix of organic additives, Pl.Br.1, presenting a much higher retained water value in relation to all other mortar mixes, while Pl.Br.2, which is of the same composition with Pl.Br.1, but with the addition only of superplasticizer and no other organic additives, presented by far the lowest retained water value. The hydraulic lime mortar presented the highest value of bulk density, while the lime-metakaolin mortar without superplasticizer and Pl.Br.1 presented the lowest values.

\subsubsection{Study of Chemical Evolution with Time}

After mixing the mortars, they were cast into steel molds $(16 \mathrm{~cm} \times 4 \mathrm{~cm} \times 4 \mathrm{~cm})$, stored in high moisture conditions $\left(25^{\circ} \mathrm{C}\right.$ and $99 \%$ relative humidity), demolded after 3 days, and stored for another 4 days in the same conditions. The samples were then left in an environment of $25^{\circ} \mathrm{C}$ and $65 \%$ relative humidity. Pl.Br.1 could not be demolded until the tenth day, indicating that the organic additives prohibited setting and hardening processes in high humidity conditions, which poses a problem in the specific reconstruction due to the environment of the structure. For this reason, specimens of the latter synthesis were also produced and left from day 0 in laboratory conditions (relative humidity $65 \%$ ), in order to compare characteristics of the hardened at mortar at 28 days (Pl.Br.1_inlab); however, it must be stressed that these conditions are not similar to those of the Plaka Bridge, and this was done only for comparison reasons. 
Simultaneous thermal analysis was conducted on pulverized samples of the mortar specimens at three ages (14, 28 and 90 days). The pulverized samples were placed in a furnace at $60^{\circ} \mathrm{C}$ for two hours and in a desiccant for one hour, prior to the measurements, in order for the results to be comparable. The recorded mass changes for different temperature ranges are presented in Table 12. The mass loss demonstrated below $120^{\circ} \mathrm{C}$ is related to physically bound water; the mass loss between $120-600{ }^{\circ} \mathrm{C}$ is related to water chemically bound to hydraulic compounds and water chemically bound in unreacted portlandite. In order to calculate the mass loss connected with hydraulic compounds, the mass loss related to the dehydroxylation of portlandite was determined and excluded from the total mass loss in this temperature range (portlandite dehydroxylation was noticed in the temperature range $370-470{ }^{\circ} \mathrm{C}$, when present, far right column of mass losses in Table 12). The amount of unreacted portlandite is important in the assessment of a restoration mortar, as it is related to the setting and hardening process of the mortar and connected to the acquisition of mechanical strength values through time. In the case of the Plaka Bridge, it is exceedingly important for portlandite to be consumed at early ages, as due to its relatively high solubility in water and taking into account the position of the structure over the Arachthos river, dissolution processes and leaching might occur. The mass loss in temperatures above $600{ }^{\circ} \mathrm{C}$ is related to the decomposition of calcite; thus, the formation of calcite can be monitored for different mortar ages. It should be noted that Pl.Br.1 and Pl.Br.2, as stated in Table 10, contain a mix of siliceous and calcareous sand; therefore, higher mass loss is expected in these mixes for the specific temperature range. The inverse hydraulicity ration, which is the ratio of mass loss connected to the decomposition of calcite to the mass loss attributed to the loss of water chemically bound to hydraulic compounds, is also calculated in Table 12, in order to assess the hydraulicity of the restoration mortars and compare with the hydraulicity of the historical mortars. It is noted that lower values of inverse hydraulicity correspond to mortars of higher hydraulicity.

Table 12. Mass loss (\%) of mortar samples in different temperature ranges and inverse hydraulicity ration.

\begin{tabular}{|c|c|c|c|c|c|c|c|}
\hline \multirow{2}{*}{$\begin{array}{l}\text { Restoration } \\
\text { Mortar }\end{array}$} & \multirow[b]{2}{*}{ Days } & \multicolumn{5}{|c|}{ Mass loss $(\%)$ in Different Temperature Ranges $\left({ }^{\circ} \mathrm{C}\right)$} & \multirow{2}{*}{$\begin{array}{c}\text { Inverse Hydraulicity } \\
\text { Ration }\end{array}$} \\
\hline & & $<120^{\circ} \mathrm{C}$ & $120-200{ }^{\circ} \mathrm{C}$ & $200-600{ }^{\circ} \mathrm{C}$ & $600-1000{ }^{\circ} \mathrm{C}$ & $370-470{ }^{\circ} \mathrm{C}$ & \\
\hline L_M8,5 & 14 & 0.97 & 0.96 & 2.28 & 8.19 & 0.45 & 2.94 \\
\hline L_M8,5 & 28 & 0.99 & 1.05 & 2.32 & 8.28 & 0.51 & 2.90 \\
\hline L_M8,5 & 90 & 0.90 & 0.99 & 2.31 & 8.06 & 0.27 & 2.66 \\
\hline L_M8,5_s & 14 & 1.02 & 1.26 & 2.92 & 7.16 & 0.89 & 2.18 \\
\hline L_M8,5_s & 28 & 0.94 & 0.98 & 2.72 & 8.75 & 0.62 & 2.84 \\
\hline L_M8,5_s & 90 & 1.01 & 0.81 & 2.21 & 9.29 & 0.00 & 3.08 \\
\hline NHL_M1 & 14 & 1.13 & 0.84 & 2.04 & 7.56 & 0.62 & 3.35 \\
\hline NHL_M1 & 28 & 0.83 & 0.52 & 1.86 & 7.62 & 0.62 & 4.33 \\
\hline NHL_M1 & 90 & 0.70 & 0.47 & 2.03 & 8.40 & 0.00 & 3.36 \\
\hline Pl.Br.1 & 14 & 0.53 & 0.59 & 4.23 & 16.66 & 1.33 & 4.77 \\
\hline Pl.Br.1 & 28 & 0.69 & 0.67 & 3.93 & 17.83 & 1.11 & 5.11 \\
\hline Pl.Br.1_ons & 28 & 0.45 & 0.49 & 4.07 & 18.29 & 1.10 & 5.29 \\
\hline Pl.Br.1 & 90 & 0.79 & 0.89 & 4.06 & 16.40 & 0.63 & 3.80 \\
\hline Pl.Br.2 & 14 & 0.63 & 0.58 & 2.65 & 17.91 & 0.71 & 7.11 \\
\hline Pl.Br.2 & 28 & 0.55 & 0.50 & 2.10 & 18.08 & 0.42 & 8.29 \\
\hline Pl.Br.2 & 90 & 0.72 & 0.73 & 2.68 & 17.87 & 0.00 & 5.24 \\
\hline
\end{tabular}

The lime-metakaolin mortars present similar mass losses in the temperature range $<120{ }^{\circ} \mathrm{C}$, around 1\%. NHL_M1 presents a decreasing amount of physically absorbed water, calculated at $0.70 \%$ at 90 days. Pl.Br.1 and Pl.Br.2 both present values below 1\%. All mortars present hydraulicity, with inverse hydraulicity values below the threshold value of 7.5. Furthermore, the inverse hydraulicity values exhibited by the restoration mortars are in the range of the hydraulicity values exhibited by the historical mortars, as previously stated [32]. Taking into account the historical materials, as well as defined acceptability limits regarding the inverse hydraulicity ration and $\mathrm{CO}_{2}$ mass loss $\%$ [45] for restoration mortars, the values measured for the different restoration mortars are within acceptability limits. 
The two lime-metakaolin mortars presented the earliest and highest consumption of portlandite in relation to all other samples (mass loss between $370-470{ }^{\circ} \mathrm{C}$ : Dehydroxylation of portlandite, endothermic peak at $\sim 440^{\circ} \mathrm{C}$ ), taking into account that the initial portlandite percentage was much higher in these mortars in relation to the other, produced with natural hydraulic lime. This affirms the high reactivity of metakaolin when used as a pozzolanic additive. It seems that even a small addition of superplasticizer can delay portlandite consumption, as the lime-metakaolin mortar with the addition of the superplasticizer, although presenting relatively low portlandite presence both at 14 and 28 days presents higher percentages that the lime-metakaolin mortar without superplasticizer. However, at 3 months curing, this is reversed, with the lime-metakaolin mortar without superplasticizer still presenting a small amount of portlandite and the one with superplasticizer presenting no amount of unreacted portlandite. The mortar with the addition of the various additives (Pl.Br.1) presented the highest mass loss in this range, indicating unreacted portlandite, even though it is a hydraulic lime mortar with a low initial percentage of portlandite. An interesting observation is that the specimen of this mortar, which was cured in laboratory conditions and did not undergo curing in high humidity conditions, presented similar values to the cured specimen. Portlandite decreases with time for all mortar mixes, as expected, while at three months curing, all portlandite has been consumed except in the case of L_M8,5, where a small amount is still present, and Pl.Br.1, where a relatively higher amount is still present.

The higher percentages of mass loss in the temperature range $>600{ }^{\circ} \mathrm{C}$, exhibited by the Pl.Br.1 and Pl.Br.2 mortars, are of course attributed not to a higher carbonation of portlandite but to the nature of the aggregates, which were a mix a siliceous sand and limestone, as this is the temperature range where calcite decomposes (endothermic peak $\sim 790^{\circ} \mathrm{C}$ for all samples, except Pl.Br.1 and Pl.Br.2, containing limestone aggregates where it is $\sim 820^{\circ} \mathrm{C}$ ).

\subsubsection{Analysis of Microstructural Characteristics}

The restoration mortars were examined in relation to their microstructural characteristics. It must be taken into account that the microstructure of a mortar transforms as time progresses until chemical reactions are complete. However, measuring microstructural characteristics at 90 days age can provide quite satisfactory indicative information regarding its final characteristics, while in combination with measurements at different curing times, it can provide information regarding the manner in which microstructure is developed.

In Table 13, the values of the microstructural characteristics of the produced restoration mortars are stated, at 90 days mortar age, as well as the range of values exhibited by the historical mortars of Plaka bridge [31,32], for comparison reasons and aiming at compatibility in terms of microstructural characteristics among the restoration mortar and the historical mortars.

Table 13. Microstructural characteristics of restoration mortars at one month, along with range of values of historical mortars.

\begin{tabular}{cccccc}
\hline Sample & $\begin{array}{c}\text { Total } \\
\text { Cumulative } \\
\text { Volume } \\
\left(\mathbf{m m}^{\mathbf{3}} \mathbf{g}\right)\end{array}$ & $\begin{array}{c}\text { Specific } \\
\text { Surface Area } \\
\left(\mathbf{m}^{2} / \mathbf{g}\right)\end{array}$ & $\begin{array}{c}\text { Average Pore } \\
\text { Radius }(\boldsymbol{\mu m})\end{array}$ & $\begin{array}{c}\text { Total } \\
\text { Porosity } \mathbf{( \% )})\end{array}$ & $\begin{array}{c}\text { Bulk } \\
\text { Density } \\
\left(\mathbf{g} / \mathbf{c m}^{\mathbf{3}}\right)\end{array}$ \\
\hline L_M8,5 & 228.16 & 9.79 & 0.62 & 36.40 & 1.60 \\
L_M8,5s & 214.58 & 9.06 & 0.48 & 34.87 & 1.62 \\
NHL_M1 & 153.97 & 4.66 & 0.37 & 28.58 & 1.86 \\
Pl.Br.1 & 239.44 & 4.34 & 0.66 & 37.16 & 1.55 \\
Pl.Br.2 & 192.16 & 4.85 & 0.63 & 32.91 & 1.71 \\
\hline $\begin{array}{c}\text { Historical } \\
\text { mortars }\end{array}$ & $\mathbf{1 9 4 - 4 1 8}$ & $\mathbf{1 9 . 5 - 4 9 . 5}$ & $\mathbf{0 . 0 1 3 - 0 . 0 4 7}$ & $\mathbf{3 1 . 6 - 4 8 . 1}$ & $\mathbf{1 . 1 1 - 1 . 6 3}$ \\
\hline
\end{tabular}


The addition of a very small amount of superplasticizer in the lime-metakaolin mortar seems to have a moderate effect on the microstructural characteristics, slightly lowering total cumulative volume, specific surface area, average pore radius, and total porosity and slightly increasing bulk density of the mortar. The natural hydraulic lime mortar with the addition of a small amount of metakaolin presented the lowest average pore radius, though lower total porosity values and total cumulative volume in relation to the historical mortars, and in fact, the lowest of all examined mortars, and a bulk density value quite higher than the historical mortars and the highest of all mortars examined. Mortar Pl.Br.1 presented a slightly higher porosity, average pore radius and total cumulative volume value than the lime-metakaolin mortar, though lower bulk density and lower specific surface area. Mortar Pl.Br.2 presents intermediate characteristics between the natural hydraulic lime mortar (NHL_M1) and the rest of the examined mortars.

The lime-metakaolin mortars presented pores in the same ranges, as well as similar cumulative volume curves, with two peaks, below $0.1 \mu \mathrm{m}$ and below $1 \mu \mathrm{m}$. However, it can be noticed that the addition of the superplasticizer slightly shifted the microstructure towards pores below $0.1 \mu \mathrm{m}$ (Figure 7). The natural hydraulic lime presents a similar distribution of pores, though a lower volume of pores for the whole range. In the cases of Pl.Br.1 and Pl.Br.2, the distribution is tighter, with a large accumulation of pores in the range between 0.1 to $1 \mu \mathrm{m}$ pore radius, as well as some pores above and around $10 \mu \mathrm{m}$ (Figure 8). Pl.Br.2, in comparison to Pl.Br.1, presents more pores between 0.01 and $0.1 \mu \mathrm{m}$. Pl.Br.1 presented a higher pore volume for all pore ranges.
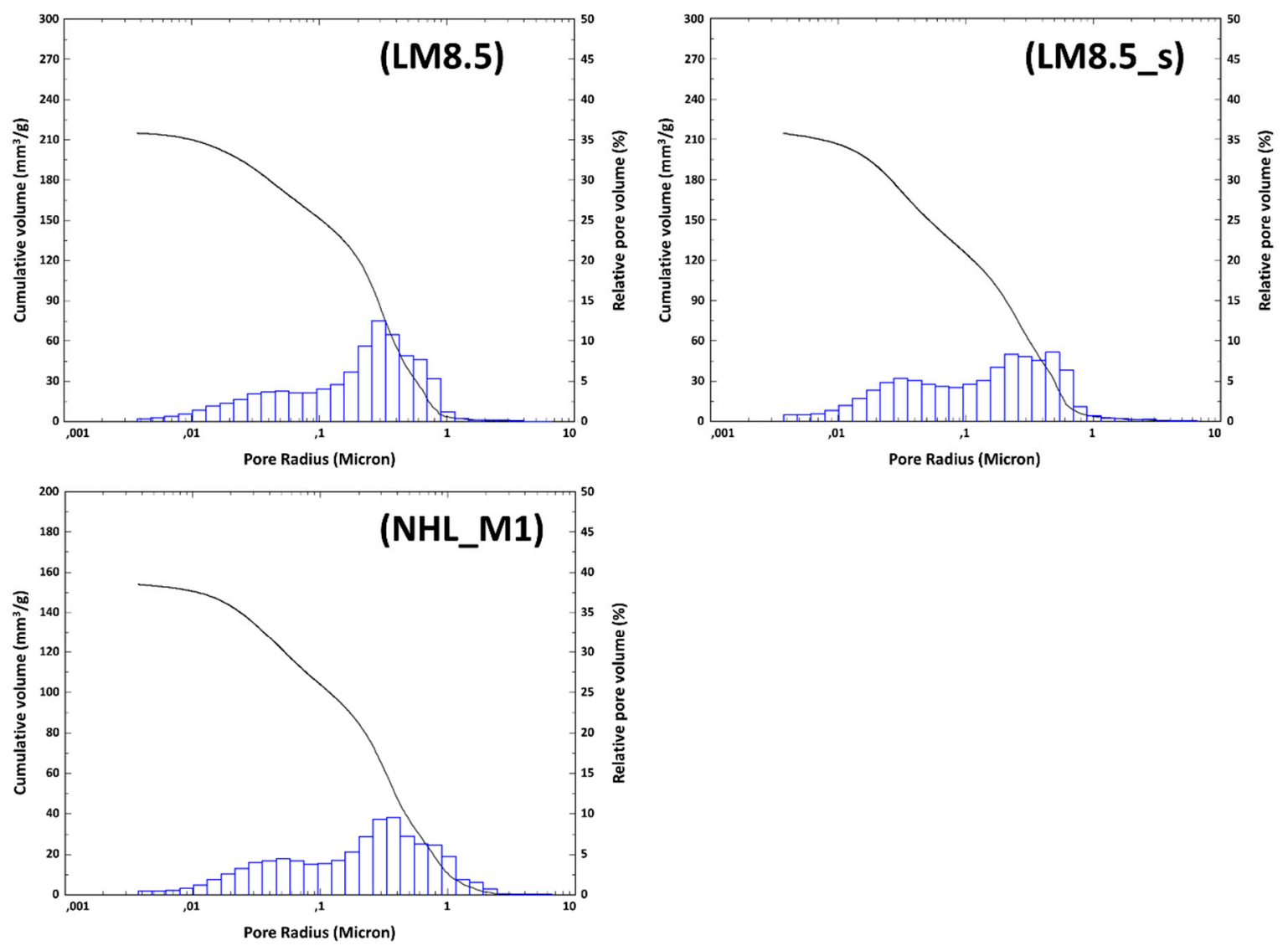

Figure 7. Cumulative volume $\left(\mathrm{mm}^{3} / \mathrm{g}\right)$ of restoration mortars L_M8.5, L_M8.5s and NHL_M1 in relation to average pore radius $(\mu \mathrm{m})$. 

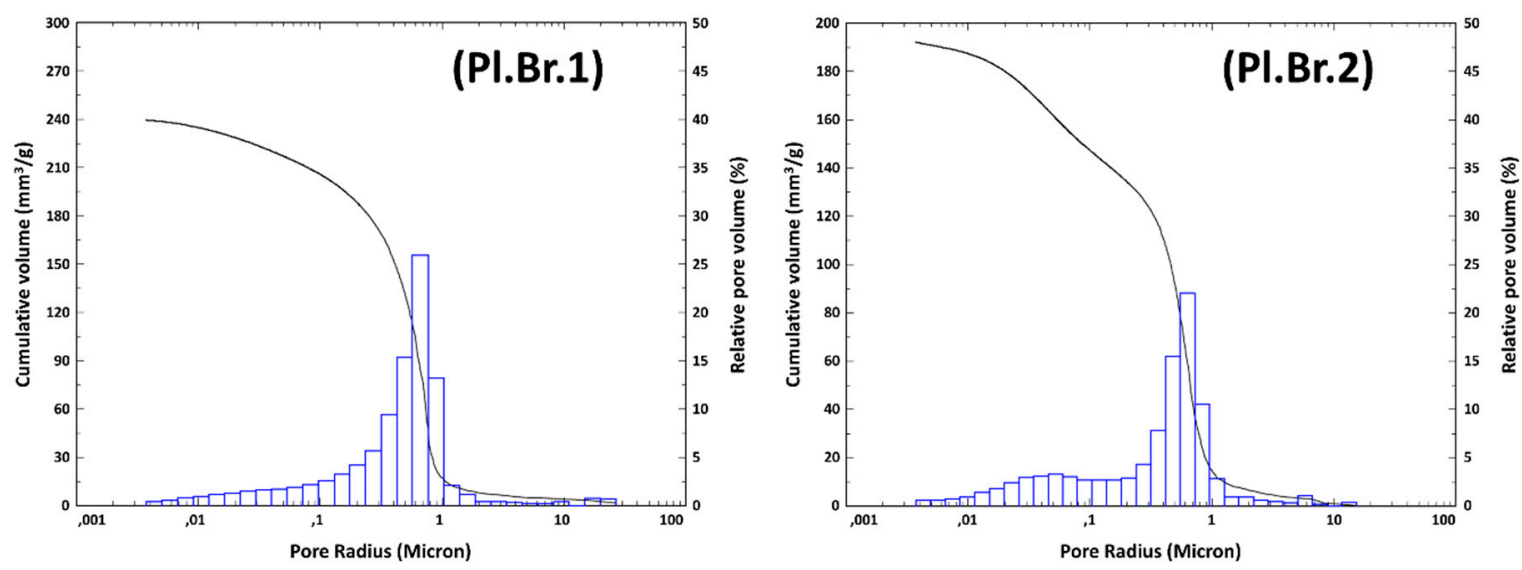

Figure 8. Cumulative volume $\left(\mathrm{mm}^{3} / \mathrm{g}\right)$ of restoration mortars $\mathrm{Pl} . \mathrm{Br} 1$ and $\mathrm{Pl} . \mathrm{Br} 2$ in relation to average pore radius $(\mu \mathrm{m})$.

The two lime-metakaolin mortars, as well as the mortar with the various additives (Pl.Br.1), are within the value ranges of the historical materials regarding all characteristics, except for the average pore radius (Figure 7); however, Pl.Br.1 presents a very tight pore distribution (Figure 8).

\subsubsection{Analysis of Mechanical Characteristics}

Flexural and compressive strength measurements were conducted on mortar specimens at 14, 28, and 90 days in accordance with Reference [27], aiming to reveal the evolution of mechanical properties with mortar age (Table 14).

Table 14. Average compressive and flexural strength of restoration mortars with standard deviation (StDev).

\begin{tabular}{cccccc}
\hline $\begin{array}{c}\text { Restoration } \\
\text { Mortar }\end{array}$ & $\begin{array}{c}\text { Age } \\
\text { (days) }\end{array}$ & $\begin{array}{c}\text { Flexural Strength } \\
\text { (Mpa) }\end{array}$ & StDev & $\begin{array}{c}\text { Compressive } \\
\text { Strength (Mpa) }\end{array}$ & StDev \\
\hline \multirow{2}{*}{ L_M8,5 } & 14 & 0.92 & 0.08 & 5.25 & 0.47 \\
& 28 & 1.58 & 0.07 & 6.65 & 0.45 \\
& 90 & 1.37 & 0.21 & 5.90 & 0.14 \\
\hline \multirow{2}{*}{ L_M8,5_s } & 14 & 1.31 & 0.48 & 6.33 & 0.73 \\
& 28 & 1.75 & 0.16 & 9.27 & 0.53 \\
& 90 & 1.12 & 0.66 & 7.47 & 0.39 \\
\hline \multirow{2}{*}{ NHL_M1 } & 14 & 1.24 & 0.04 & 2.87 & 0.10 \\
& 28 & 1.31 & 0.06 & 4.48 & 0.10 \\
& 90 & 1.62 & 0.13 & 5.52 & 0.17 \\
\hline \multirow{2}{*}{ Pl.Br.1 } & 14 & 0.46 & 0.02 & 0.00 & 0.00 \\
& 28 & 1.41 & 0.15 & 2.83 & 0.21 \\
& 90 & 2.83 & 0.12 & 7.08 & 0.26 \\
\hline \multirow{2}{*}{ Pl.Br.2 } & 14 & 0.84 & 0.12 & 2.80 & 0.06 \\
& 28 & 0.85 & 0.04 & 4.83 & 0.18 \\
& 90 & 0.83 & 0.14 & 7.67 & 0.36 \\
\hline
\end{tabular}

Regarding the lime-metakaolin mortars, early acquirement of compressive strength was achieved for both mortars (over $5 \mathrm{MPa}$ at 14 days), while flexural strength also reached satisfactory values at 14 days. The use of superplasticizer, even in the small amount added, increased flexural strength by about $10 \%$ and compressive strength by almost $40 \%$ (at 28 days). However, at 90 days, average flexural strength values of L_M8.5s decreased to a value lower than that of L_M8.5, with a high standard deviation between measurements. This could indicate anisotropy due to the effect of the superplasticizer. 
Both lime-metakaolin mortars presented a decrease in both flexural and compressive strength values at 90 days in relation to 28 days, as noticed by other researchers as well in lime-metakaolin mortars.

The natural hydraulic lime mortar, NHL_M1, although presenting lower mechanical strength values than the lime-metakaolin mortars at 28 days, reached higher values of flexural strength at 90 days; this is due to the continuous development of flexural strength of NHL_M1 until this age in combination with the decrease of the lime-metakaolin mortars' flexural strength from 28 to 90 days. In terms of compressive strength, it continued to increase with mortar age up to 90 days, achieving a compressive strength value above $5 \mathrm{MPa}(\sim 5.5 \mathrm{MPa})$.

Pl.Br.1, with the use of various additives, did not present any compressive strength at 14 days, as the mortar specimens had not hardened enough to undergo the measurement. It presented the lowest compressive strength value at 28 days, though an adequate flexural strength value at this time. At 90 days this mortar presented the highest overall values of flexural and compressive strength among the studied mortar mixes.

Pl.Br.2, the natural hydraulic lime mortar with the mix of natural pozzolan and metakaolin and the addition only of superplasticizer, presented the lowest flexural strength values, which did not seem to increase at all up to 90 days. However, compressive strength continued to increase from 14 days to 90 days, reaching a high value, the highest of the mortars examined.

Both the lime-metakaolin mortars and Pl.Br.1 seem to be appropriate in terms of mechanical properties and demanded efficiency for use in the restoration.

\subsubsection{Adherence of the Different Mortars to the Quarry Stone as a Substrate-Pull-Off Resistance}

Pull-off tests were conducted in order to estimate the adhesive strength of the restoration mortars [28]. As described in a previous section, it was decided to use the quarry stone in order to examine this property, in order to be closer to real-time parameters. The different restoration mortars were applied on a pavement stone, and the stone tiles were applied on the restoration mortars, after wetting the surface in contact with the mortar. In this preliminary stage of research, this process was implemented for mortars Pl.Br.1, Pl.Br.2, and NHL_M1, and tests were conducted after 28 days. Thus, at 28 days, special metal cylinders were glued on the top surface of the stone tiles, and the force required to detach the stone tiles from the mortars was measured with a Pruf system instrument (Table 15, Figure 9). The results indicate the better adhesion of NHL_M1 and Pl.Br.2 to the quarry stone.

Table 15. Pull-off test results.

\begin{tabular}{cccc}
\hline Mortar & Pull-off Force (kN) & $\begin{array}{c}\text { Mortar Adhesive } \\
\text { Strength (MPa) }\end{array}$ & Area of Detachement \\
\hline NHL_M1 & 0.229 & 0.09 & $\begin{array}{c}\text { Mortar and stone detached from } \\
\text { upper surface of pavement stone, } \\
\text { mortar presents adhesion to stone } \\
\text { tile after detachment (Figure 9d) }\end{array}$ \\
Pl.Br.1 & 0 & $\begin{array}{c}\text { Mortar completely detached from } \\
\text { pavement stone - then easily } \\
\text { detached manually from stone tile } \\
\text { (Figure 9b) }\end{array}$ \\
\hline Pl.Br.2 & 0.371 & 0.15 & $\begin{array}{c}\text { Stone tile and upper part of } \\
\text { mortar were detached from lower } \\
\text { part of mortar and pavement } \\
\text { stone (as in Figure 9d) }\end{array}$ \\
\hline
\end{tabular}



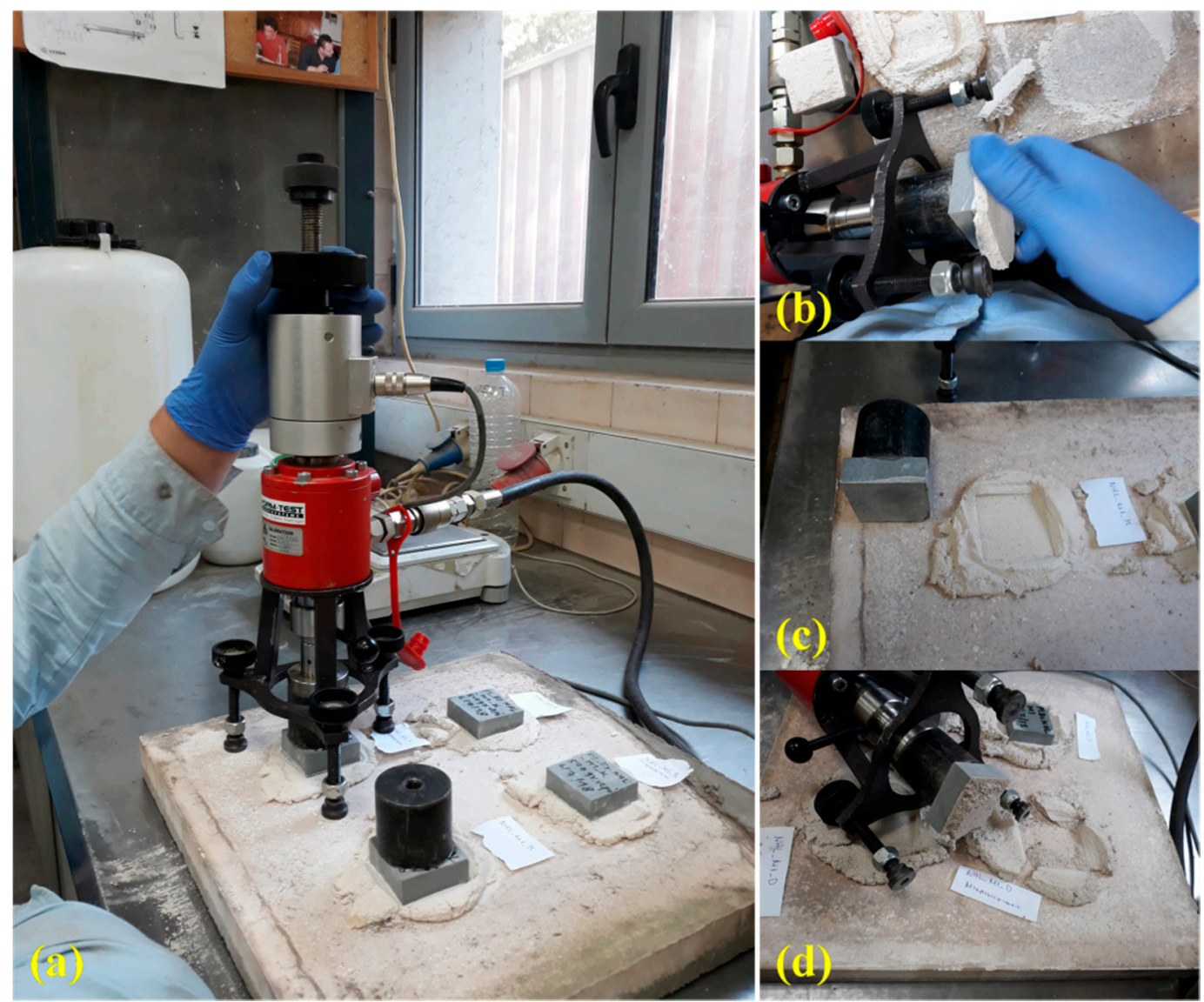

Figure 9. Different pull-off tests results; (a) in the process of the pull-off test, (b) stone-mortar system detached from pavement stone (mortar easily detached from the stone manually indicating no adherence), (c) stone detaching from the mortar completely, indication of no adherence, (d) stone detached with upper part of mortar, lower part of mortar remains on pavement stone.

\section{Conclusions}

This study demonstrated the manner in which compatible and performing restoration materials can be designed and selected for restoration projects, taking into account the historical materials. As discussed, this is particularly important in the case of stone bridge structure restoration interventions, in order to serve in the aggressive environment and dynamic stresses they are subjected to and improve the sustainability of the structure. In order to achieve an overall homogeneous behavior of the restored structure, compatibility between the historical stone and the restoration stones, as well as compatibility between the historical mortars and the restoration mortar, must be ensured. The present study illustrates how the compatibility assessment of different materials can be achieved using appropriate analytical and nondestructive techniques.

The "Dafnoula" stone from a local quarry near the Plaka Bridge location presented similar mineralogical, chemical characteristics, as well as hygric, mechanical, and aesthetic properties with the compact stone of the historical bridge structure. This is indicative that the building stone used in the original construction was probably also quarried in the area. As the historical stone has shown good durability in this environment throughout the two centuries from the bridge's construction, a similar stone with similar characteristics is highly desirable.

Restoration mortars were designed based on the historical mortars of the Plaka Bridge, through a reverse engineering methodological approach. The historical mortars, as discussed, were lime-based hydraulic mortars. It was therefore decided to design restoration mortars of corresponding hydraulicity, using two different binders: Aerial lime with the addition of metakaolin, a highly reactive pozzolan, and hydraulic lime, also with the addition of pozzolan. The restoration mortars were evaluated on the 
basis of the historical mortars' measured characteristics, while other considerations were taken into account, such as early acquisition of mechanical strength and early consumption of portlandite, issues important for bridge construction.

The results show that the lime-metakaolin restoration mortars present the appropriate characteristics both to be compatible with the historical mortar in terms of hydraulicity and microstructure, as well as to be effective in relation to mechanical properties, thus ensuring the mechanical behavior and response of the bridge. Furthermore, through the use of metakaolin as a pozzolanic additive, early acquisition of mechanical strength is achieved, an issue of paramount importance in such a difficult and demanding restoration project. The use of organic additives in the mortar mixes, although leading to higher mechanical strength values at 90 days, presented several drawbacks, mainly their different microstructure in relation to the historical mortars, as well as a delayed acquirement of mechanical strength. The natural hydraulic lime mortar with a small percentage of metakaolin also presented a lower rate of early mechanical strength development, while presenting the highest bulk density among all restoration mortars herein examined. Thus, it is highly recommended to use a lime-metakaolin mortar with siliceous aggregates in order to achieve compatibility and performance and at the same time be consistent with the construction materials of the past, ultimately contributing to an increased resilience of the structure as a whole.

The Plaka Bridge is a case where the historical materials presented good behavior against the prevailing environmental factors, even though anthropogenic and extreme events resulted in its partial collapse, thus serving as a basis for the design of appropriated restoration materials for historical stone bridges. The builders of the past, although employing empirical rules, designed and applied materials highly appropriate for each unique construction and environment. The challenge for research and practice today is to preserve these historical materials, as well as to unravel the latent knowledge hidden within these structures.

Author Contributions: M.A. wrote and edited the paper, supervised the investigation related to restoration mortars and implemented the investigation related to thermal analysis investigations; I.N. implemented the investigation related to the historical and quarry stones; I.G. implemented the investigation connected to the restoration mortars (natural hydraulic lime-based); M.K. (Myrto Kalofonou) implemented the investigation connected to the restoration mortars (lime-metakaolin); V.K. assisted in the in situ investigation and sampling collection; E.T.D. participated in the investigation of the historical mortars during the diagnostic study, the values of which were used in the current research in order to assess compatibility, offered the methodology concerning material characterization, and supervised mineralogical examination measurements, as well as the aesthetical compatibility related investigation; M.K. (Maria Karoglou) offered the methodology related to hygric behavior measurements and supervised the related measurements; A.B. implemented the investigation related to the materials' microstructure; K.C.L. participated in the in situ investigations, as well as in the revision and final preparation of the paper; C.M. supervised all in situ activities and investigations; A.M. had the scientific supervision of the NTUA team and all related measurements, offered the overall methodology and visualization, designed all aspects of the research conducted, and supervised the overall writing of the paper. All authors contributed to the writing of the paper in their respective areas of investigation.

Funding: This research received no external funding. It was part of the pro bono interdisciplinary work of the National Technical University of Athens conducted within the NTUA Interdisciplinary team for the Plaka Bridge restoration; an offer to Epirus, as a return to the birthplace of the founders of the National Technical University of Athens.

Acknowledgments: The authors would like to acknowledge the valuable contributions and the fruitful cooperation within the NTUA Interdisciplinary team for the Plaka Bridge restoration, with NTUA Rector Prof. I. Golias, as scientific responsible and professor D. Kaliampakos, as coordinator. Further, the Ministry of Culture and Sports of the Hellenic Republic and its Scientific Committee for the Plaka Bridge restoration, and particularly the President of the Scientific Committee, NTUA professor emeritus M. Korres, for his cooperation and insights. The authors would like to thank local builder K. Pliakopanos for his assistance during onsite visits, as well as A. Papakostopoulos, contractor of the restoration project, and his consultant, S. Konstantinides, for their valuable assistance in aspects regarding the upcoming restoration project. The authors would also like to thank TITAN S.A. and the company scientists and employees for their cooperation in issues related to the restoration mortars. The authors would like to thank Sophia Mermiggi, chemical engineer, for her valuable assistance in the in situ measurements and sampling procedure. This research was orally presented in its initial form at the 1st International Conference TMM_CH: Transdisciplinary Multispectral Modelling and Cooperation for the Preservation of Cultural Heritage, held on 10-13 October 2018 at the Eugenides Foundation Athens, Greece under the title "The Plaka Bridge in Epirus: An Evaluation of New Building Materials for its Restoration" by M. Apostolopoulou, I. Nikolaidis, I. 
Grillakis, V. Keramidas, S. Mermiggi, E.T. Delegou, M. Karoglou, A. Bakolas, Ch. Mouzakis and A. Moropoulou, and has since then been modified and elaborated with further results and interpretations. This study is dedicated to the memory of our beloved colleague, the late Petros Moundoulas, who contributed to the study of the Plaka Bridge historical mortars.

Conflicts of Interest: The authors declare no conflict of interest.

\section{References}

1. Solla, M.; Riveiro, B.; Lorenzo, H.; Armesto, J. Ancient stone bridge surveying by ground-penetrating radar and numerical modeling methods. J. Bridge Eng. 2013, 19, 110-119. [CrossRef]

2. Oliveira, D.V.; Lourenço, P.B.; Lemos, C. Geometric issues and ultimate load capacity of masonry arch bridges from the northwest Iberian Peninsula. Eng. Struct. 2010, 32, 3955-3965. [CrossRef]

3. Witzany, J.; Cejka, T.; Zigler, R. Failure resistance of the historic stone bridge structure of Charles Bridge. I: Susceptibility to nonstress effects. J. Perform. Constr. Facil. 2008, 22, 71-82. [CrossRef]

4. Conde, B.; Díaz-Vilariño, L.; Lagüela, S.; Arias, P. Structural analysis of Monforte de Lemos masonry arch bridge considering the influence of the geometry of the arches and fill material on the collapse load estimation. Constr. Build. Mater. 2016, 120, 630-642. [CrossRef]

5. Witzany, J.; Cejka, T.; Zigler, R. Failure resistance of historic stone bridge structure of Charles bridge. II: Susceptibility to floods. J. Perform. Constr. Facil. 2008, 22, 83-91. [CrossRef]

6. Papayianni, I.; Pachta, V.; Alexiou, A. Study of the constructing materials, techniques and pathology symptoms of the stone bridge DeBosset in Kefalonia. In Proceedings of the 5th International Conference on Arch Bridges, Madeira, Protugal, 12-14 September 2007.

7. Přikryl, R.; Weishauptová, Z.; Novotná, M.; Přikrylová, J.; Št'astná, A. Physical and mechanical properties of the repaired sandstone ashlars in the facing masonry of the Charles Bridge in Prague (Czech Republic) and an analytical study for the causes of its rapid decay. Environ. Earth Sci. 2011, 63, 1623-1639. [CrossRef]

8. Costa, C.; Arêde, A.; Morais, M.; Aníbal, A. Detailed FE and DE modelling of stone masonry arch bridges for the assessment of load-carrying capacity. Procedia Eng. 2015, 114, 854-861. [CrossRef]

9. Tran, V.H.; Vincens, E.; Morel, J.C.; Dedecker, F.; Le, H.H. 2D-DEM modelling of the formwork removal of a rubble stone masonry bridge. Eng. Struct. 2014, 75, 448-456. [CrossRef]

10. Manos, G.C.; Simos, N. The Structural Performance of Stone Masonry Bridges (No. BNL-113148-2016-BC; Brookhaven National Laboratory (BNL): Upton, NY, USA, 2016.

11. Moropoulou, A.; Lampropoulos, K.; Sotiropoulos, P.; Papageorgiou, C. The Plaka Bridge in Epirus: Ground penetrating radar prospection of surviving parts of the collapsed bridge, to provide structural information for its reconstruction. In Nondestructive Evaluation and Monitoring Technologies, Documentation, Diagnosis and Preservation of Cultural Heritage; Osman, A., Moropoulou, A., Eds.; Springer Nature Switzerland AG: Cham, Switzerland, in print.

12. Hyz, A.; Karamanis, K. Epirus: Introducing the Region. In Creative Industries in Greece; Hyz, A., Karamanis, K., Eds.; Palgrave Macmillan: Cham, Switzerland, 2016; pp. 49-72.

13. Karaveziroglou-Weber, M.; Stavrakakis, E.; Karayianni, E. Damages on existing stone bridges in Greece. In Proceedings of the 2nd International Conference on Arch Bridges, Venice, Italy, 6-8 October 1998; Sinopolis, A., Ed.; pp. 361-367.

14. Stathopoulou, E.K.; Georgopoulos, A.; Panagiotopoulos, G.; Kaliampakos, D. Crowd Sourcing Lost Cultural Heritage. ISPRS Ann. Photogramm. Remote Sens. Spat. Inf. Sci. 2015, 295-300. [CrossRef]

15. Gkolias, I. The Bridge of Plaka: The NTUA Contribution towards Its Restoration; NTUA: Athens, Greece, 2018.

16. Armaly, M.; Blasi, C.; Hannah, L. Stari Most: Rebuilding more than a historic bridge in Mostar. Mus. Int. 2004, 56, 6-17. [CrossRef]

17. Giannakopoulou, S.; Damigos, D.; Kaliampakos, D. The socioeconomic value of the Plaka Bridge in mountainous Epirus. In Proceedings of the 19th International Conference on Cultural Economics, Valladolid, Spain, 21-24 June 2016.

18. UNI. Beni culturali-Malte Storiche e da Restauro-Metodi di Prova per la Caratterizzazione Chimica di Una Malta-Analisi Chimica. UNI 11189, 2006.

19. Moropoulou, A.; Bakolas, A.; Bisbikou, K. Characterization of ancient, byzantine and later historic mortars by thermal analysis and X-ray diffraction techniques. Thermochim. Acta 1995, 269, 779-795. [CrossRef] 
20. CNR-ICR. Normal 34/91: Analysis of Clay Materials by XRD Rome; Consiglio Nazionale delle Ricerche and Istituto Centrale del Restauro (CNR-ICR): Rome, Italy, 1991.

21. CNR-ICR. Normal 4/80: Distribution of Pore Volume as a Function of Pore Diameter C.N.R.-I.C.R.; Consiglio Nazionale delle Ricerche and Istituto Centrale del Restauro (CNR-ICR): Rome, Italy, 1980.

22. British Standards Institution. EN15801: 2010: Conservation of Cultural Property-Test Methods-Determination of Water Absorption by Capillarity; European Commitee for Standardisation: Brussels, Belgium, 2010.

23. British Standards Institution. EN15886:2010: Conservation of Cultural Property-Test Methods-Colour Measurement of Surfaces; European Commitee for Standardisation: Brussels, Belgium, 2010.

24. British Standards Institution. EN1015-3:2007: Methods of Test for Mortar for Masonry-Part 3. Determination of Consistence of Fresh Mortar (by Flow Table); European Commitee for Standardisation: Brussels, Belgium, 2007.

25. British Standards Institution. EN1015-6:2007: Methods of Test for Mortar for Masonry-Part 6: Determination of Bulk Density of Fresh Mortar; European Commitee for Standardisation: Brussels, Belgium, 2007.

26. British Standards Institution. EN1015-8:2007: Methods of Test for Mortar for Masonry-Part 8. Determination of Retained Water of Fresh Mortar; European Commitee for Standardisation: Brussels, Belgium, 2007.

27. British Standards Institution. EN1015-11:2007: Methods of Test for Mortar for Masonry—Part 11. Determination of Flexural and Compressive Strength of Hardened Mortars; European Commitee for Standardisation: Brussels, Belgium, 2007.

28. British Standards Institution. EN1015-12:2007: Methods of Test for Mortar for Masonry—Part 12. Determination of Adhesive Strength of Hardened Rendering and Plastering Mortars on Substrates; European Commitee for Standardisation: Brussels, Belgium, 2007.

29. Oliveira, D.V.; Costa, V.M.; Sousa, J.F.; Lourenço, P.B. Diagnosis and repair of a historic stone masonry arch bridge. In Proceedings of the 6th International Conference on Arch Bridges (ARCH'10), Fuzhou, China, 11-13 October 2010; pp. 817-822.

30. Karagiannis, N.; Karoglou, M.; Bakolas, A.; Moropoulou, A. Building materials capillary rise coefficient: Concepts, determination and parameters involved. In New Approaches to Building Pathology and Durability; Delgado, J.M.P.Q., Ed.; Springe: Singapore, 2016; pp. 27-44.

31. Moropoulou, A.; Bakolas, A.; Delegou, E.T.; Moundoulas, P.; Apostolopoulou, M. Characterization of the historical mortars of the Plaka bridge and proposal for a new restoration mortar. In The Bridge of Plaka: The NTUA Contribution towards Its Restoration; NTUA: Athens, Greece, 2016; pp. 237-257.

32. Apostolopoulou, M.; Aggelakopoulou, E.; Bakolas, A.; Moropoulou, A. Compatible Mortars for the Sustainable Conservation of Stone in Masonries. In Advanced Materials for the Conservation of Stone; Hosseini, M., Karapanagiotis, I., Eds.; Springer: Cham, Switzerland, 2018; pp. 97-123.

33. Frankeová, D.; Slížková, Z.; Drdácký, M. Characteristics of mortars from ancient bridges. In Historic Mortars; Springer: Dordrecht, The Netherlands, 2012; pp. 165-174.

34. Bakolas, A.; Biscontin, G.; Contardi, V.; Franceschi, E.; Moropoulou, A.; Palazzi, D.; Zendri, E. Thermoanalytical research on traditional mortars in Venice. Thermochim. Acta 1995, 269, 817-828. [CrossRef]

35. Oleson, J.P.; Brandon, C.; Cramer, S.M.; Cucitore, R.; Gotti, E.; Hohlfelder, R.L. The ROMACONS Project: A contribution to the historical and engineering analysis of hydraulic concrete in Roman maritime structures. Int. J. Naut. Archaeol. 2004, 33, 199-229. [CrossRef]

36. Moropoulou, A.; Bakolas, A.; Anagnostopoulou, S. Composite materials in ancient structures. Cem. Concr. Compos. 2005, 27, 295-300. [CrossRef]

37. Vintzileou, E.; Gianellos, C.; Adami, C.E.; Tsakanika, E. Documentation of building materials mechanical characteristics. In The Bridge of Plaka: The NTUA Contribution towards Its Restoration; NTUA: Athens, Greece, 2016; pp. 227-235.

38. Apostolopoulou, M.; Aggelakopoulou, E.; Siouta, L.; Bakolas, A.; Douvika, M.; Asteris, P.G.; Moropoulou, A. A methodological approach for the selection of compatible and performable restoration mortars in seismic hazard areas. Constr. Build. Mater. 2017, 155, 1-14. [CrossRef]

39. Moropoulou, A. Reverse engineering to discover traditional technologies: A proper approach for compatible restoration mortars. In PACT No. 58; Conseil de l'Europe: Athens, Greece, 2000; pp. 81-107.

40. Moropoulou, A.; Bakolas, A.; Moundoulas, P.; Aggelakopoulou, E. Reverse engineering: A proper methodology for compatible restoration mortars. In Proceedings of the Workshop on Repair Mortars for Historic Masonry, TC RMH, Delft, The Netherlands, 26-28 Jaunary 2005; pp. 25-28. 
41. Maravelaki-Kalaitzaki, P.; Bakolas, A.; Moropoulou, A. Physico-chemical study of Cretan ancient mortars. Cem. Concr. Res. 2003, 33, 651-661. [CrossRef]

42. Aggelakopoulou, E.; Bakolas, A.; Moropoulou, A. Properties of lime-metakaolin mortars for the restoration of historic masonries. Appl. Clay Sci. 2011, 53, 15-19. [CrossRef]

43. Vejmelková, E.; Keppert, M.; Keršner, Z.; Rovnaníková, P.; Černý, R. Mechanical, fracture-mechanical, hydric, thermal, and durability properties of lime-metakaolin plasters for renovation of historical buildings. Constr. Build. Mater. 2012, 31, 22-28. [CrossRef]

44. Gameiro, A.; Santos Silva, A.; Faria, P.; Grilo, J.; Branco, T.; Veiga, R.; Velosa, A. Physical and chemical assessment of lime-metakaolin mortars: Influence of binder:aggregate ratio. Cem. Concr. Compos. 2014, 45, 264-271. [CrossRef]

45. Moropoulou, A.; Bakolas, A. Range of acceptability limits of physical, chemical and mechanical characteristics deriving from the evaluation of historic mortars. In PACT. No. 56; Conseil de l'Europe: Athens, Greece, 1998.

(C) 2019 by the authors. Licensee MDPI, Basel, Switzerland. This article is an open access article distributed under the terms and conditions of the Creative Commons Attribution (CC BY) license (http://creativecommons.org/licenses/by/4.0/). 